(C)2019, Elsevier. This manuscript version is made available under the CC-BY-NC-ND 4.0

license http://creativecommons.org/licenses/by-nc-nd/4.0/

\title{
Social media effect, investor recognition and the cross-section of stock returns
}

\author{
Xiangtong Meng \\ Collage of Management and Economic, Tianjin University, Tianjin, 300072, China \\ Wei Zhang \\ Collage of Management and Economic, Tianjin University, Tianjin, 300072, China \\ China Center for Social Computing and Analytics, Tianjin 300072, China \\ Youwei Li \\ Hull University Business School, University of Hull, HU6 7RX, United Kingdom \\ Xing Cao \\ Collage of Management and Economic, Tianjin University, Tianjin, 300072, China \\ Xu Feng* \\ Collage of Management and Economic, Tianjin University, Tianjin, 300072, China \\ China Center for Social Computing and Analytics, Tianjin 300072, China
}

\begin{abstract}
Investor recognition affects cross-sectional stock returns. In informationally incomplete markets, investors have limited recognition of all securities, and their holding of stocks with low recognition requires compensation for being imperfectly diversified. Using the number of posts on the Chinese social media platform Guba to measure investor recognition of stocks, this paper provides a direct test of Merton's investor recognition hypothesis. We find a significant social media premium in the Chinese stock market. We further find that including a social media factor based on this premium significantly improves the explanatory power of Fama-French factor models of cross-sectional stock returns, and these results are robust when we control for the mass media effect and liquidity effect. Finally, we find that investment strategies based on the social media factor earn sizable risk-adjusted returns, which signifies the importance of the social media premium in portfolio management.
\end{abstract}

\footnotetext{
*Corresponding author: fengxu@tju.edu.cn
} 
Keywords: social media; investor recognition; asset pricing

JEL Classification: G12; G14; G15 


\section{Introduction}

Media coverage is an important determinant of cross-sectional stock returns. In the mass media era, information disseminated by media such as newspapers and television affects investors' trading activities and stock prices. Fang and Peress (2009) document the impact of mass media coverage on cross-sectional stock returns and propose what they call the "mass media effect": stocks with lower mass media coverage earn higher returns. This effect has been demonstrated in various countries (Ferguson et al., 2015; Aman et al., 2018; Griffin et al., 2011; Turner et al., 2018; Zou, Cao and Wang, 2018). Fang and Peress (2009) and others explain the mass media effect through the " investor recognition hypothesis" of Merton (1987). According to this argument, mass media coverage broadens investor recognition. Stocks with lower mass media coverage is required to offer higher returns to compensate investors for holding imperfectly diversified portfolios.

With the advent of the Internet, social media have become a mainstream platform for investors to post, gather, and exchange information (Allcott and Gentzkow, 2017; Lazer et al., 2018; Lee et al., 2016). It is thus important to study the effect of social media on cross-sectional stock returns. ${ }^{1}$ Compared with mass media, social media may provide a better proxy for investor recognition of stocks. First, mass media disseminate information via a one-way route: it is difficult to know whether investors have received information, and it is not easy to determine how many investors recognize the securities in the market and to what extent. However, when investors post messages about a stock on social media platforms, they usually have a certain understanding of the stock, and it is easier to quantify their recognition of the stock. Second, social media facilitate interaction among investors, and this leads to lower information asymmetry (Miller and Skinner, 2015). Through investors' interactions and responses to online messages, those who initially had limited recognition of a stock will gain a certain level of knowledge about it. Finally, social media platforms can record investor interactions

\footnotetext{
${ }^{1}$ There are extensive studies of the relationship between social media and securities markets. Early studies discuss whether social media postings contain private information, and find that social media content is noise-based and has no statistically significant impact on stock returns (Tumarkin and Whitelaw, 2001; Das and Chen, 2007; Antweiler and Frank, 2004). In a recent study, Sprenger et al. (2014) use computational semantic analysis to classify S\&P 500-related Twitter messages into good and bad news. They find that good news has the power to predict stock returns, which may indicate that social media information is not full of noise but contains private information.
} 
and responses to online messages. These records serve as a direct measure of investor recognition, one that is not readily available in mass media.

This paper studies the social media effect on cross-sectional stock returns in China. We draw on online message posting data from Eastmoney $\mathrm{Guba}^{2}$ (henceforth Guba), the largest and most active financial social media platform in China. The Guba platform is compatible with the Guba trading app, which is widely used by Chinese investors, especially individual investors. The influence of Guba is extensive: it occupies about $5 \%$ of Web traffic in all financial websites in China, and information from Guba influences 12 million to 22 million investors per day. ${ }^{3}$ We collect nearly 100 million observations of investors posting data on the platform, which covers more than 3,000 stocks. For each stock, there is a firm-specific sub forum in Guba. So we are able to calculate monthly number of postings in each stock's sub-forum, which can be regarded as a direct measure of investor recognition of this stock. By sorting stocks into portfolios with different degrees of social media coverage, we can investigate the social media premium. If social media disseminate information to a wider audience and broaden investor recognition, we would expect to observe a significant social media premium. Next, we examine the impact of the social media premium on cross-sectional stock returns. By testing the informativeness of the social media premium, this paper identifies the risk associated with investor recognition in explaining cross-sectional stock returns. It also provides a direct test of the investor recognition hypothesis of Merton (1987).

The Chinese stock market is still developing, but China has witnessed considerable progress in applying social media to financial markets. According to a survey by McKinsey, $91 \%$ of Chinese respondents have visited a social media site recently. ${ }^{4} 83.6 \%$ of individual investors use Internetbased social media on their computers and mobile phones as their preferred source of investment information. ${ }^{5}$ The widespread use of social media platforms such as Guba in China ensures a huge data set of online postings, which is ideal for measuring investor recognition. Furthermore, the Chinese

\footnotetext{
${ }^{2}$ http://guba.eastmoney.com. In Chinese, "Gu" means stocks and "ba" means pub.

${ }^{3}$ Data Source: iResearch Consulting Group. http://www.iresearchchina.com

${ }^{4}$ Data Source: McKinsey \& Company. 2014 https://www.mckinsey.com

${ }^{5}$ Data Source: Shenzhen Stock Exchange Report on Individual Investor Status 2016
} 
stock market is dominated by individual investors (Han and Li, 2017), as individual trading accounts for more than $85 \%$ of the total volume. ${ }^{6}$ Social media mainly influence the recognition of individual investors rather than institutional investors. This unique feature facilitates a direct test of Merton's investor recognition hypothesis.

In this paper, we report a significant social media premium in the Chinese stock market. Based on this premium, we further identify the risk associated with investor recognition by constructing a social media factor. We find that adding the social media factor to the well-known Fama-French factor model significantly improves its explanatory power for cross-sectional stock returns. The results are robust when we control for the mass media effect and liquidity effect. Moreover, using social media data to measure investor recognition, we provide direct evidence in support of Merton's investor recognition hypothesis. Lastly, we find that investment strategies based on the social media factor are able to generate significant profit on a risk-adjusted basis. This paper illustrates the importance of using social media data to understand cross-sectional stock returns. It points the way for future work along these lines, including research in other areas in finance.

While we view online posting as a measure of investor recognition, we note that it is also often associated with investor sentiment ${ }^{7}$. Bollen et al. (2011) interpret social media posting as a measure of investor sentiment. They extract daily public sentiment data from Twitter and find that public sentiment has a significant correlation with market return. Among studies linking the social media effect to cross-sectional stock returns, Kim and Kim (2014) test the predictability of extracted investor sentiment for stock returns based on 32 million messages on the Yahoo! message board from 2005 to 2010. Leung and Ton (2015) use a sample of 2.5 million observations from HotCopper, an Australian financial social media platform, from 2003 to 2008, and find that stock returns are only positively related to the sentiments expressed on social media in the case of poor performance and small-cap

\footnotetext{
${ }^{6}$ Data Source: Shanghai Stock Exchange Statistics Annual 2016

${ }^{7}$ Sentiment is not considered a rational pricing factor in many studies (Hirshleifer, 2001; Xu and Green, 2012) and has no predictive power for cross-sectional stock returns (Kim and Kim, 2014). Moreover, it is hard to accurately extract investor sentiment from online messages; for instance, an accuracy of $88 \%$ is obtained by Antweiler and Frank (2004) and about $60 \%$ by Das and Chen (2007).
} 
stocks. We note that these studies focus mainly on the content of online postings rather than the number of online postings. However, to further control for possible sentiment effect, in this study we adopt common measures of sentiment such as the MAX effect (Bali et al., 2011; Fong and Toh, 2014), turnover ratio, and trading volume (Hong and Stein, 2007). We find that our main results remain unchanged after controlling for sentiment effect. This supports our interpretation of the number of online postings as a measure of investor recognition and provides further support for our arguments.

The remainder of this paper proceeds as follows. Section 2 describes in detail the data used. Section 3 provides the empirical results. Section 4 explains the social media effect based on the investor recognition hypothesis. Section 5 explores the profitability of investment strategies based on the social media premium. Section 6 concludes the paper.

\section{Data}

We collect social media data from Guba, the largest and most comprehensive financial social media platform in China, which features the highest network traffic of any comparable financial social media in China. Guba is established in 2006 to provide a financial information platform for investors to share information and opinions. At present, Guba has millions of registered users who make more than 100,000 posts per day, making it approximately 10 times larger than its closest competitors. ${ }^{8} \mathrm{Guba}$ includes all stocks that are currently trading or have been traded in the market, with independent sub-forums named according to the code or name of each stock. To post messages on Guba, investors need to know at least the name and code of the stock, which ensures that they have a certain degree of recognition of this stock before posting. We retrieve visible content from all Guba sub-communities, and use about 150 million postings. Noted that we regard all of postings in the sub-forum of one stock are associated with this stock because users should enter the sub-forum on their own initiative. Our key variable for a given stock, Gubapost, is the monthly number of all postings in its own Guba sub-forum. We use Gubapost as a proxy for investor recognition.

\footnotetext{
${ }^{8}$ Data Source: iResearch Consulting Group. http://www.iresearchchina.com.
} 
Our sample consists of all listed companies in the Chinese A-share market from January 1, 2012, to June 30, 2017. During the sample period, social media exploded into the mainstream, which ensures enough data for our research. We exclude stocks that have been listed less than a year, those with negative book value, those subject to long-term suspension ${ }^{9}$ or de-listing, and special-treatment stocks ${ }^{10}$, to ensure that stock returns correctly reflect changes in the value of the company. Given that there are little stock in these abnormal situations, the average number of stocks in our sample is about 2,500, which covers most of the stocks listed in the market and over $90 \%$ of overall market capitalisation in each period. Therefore, the firms in our sample are representative. The accounting and trading data on listed companies are obtained from the Wind database. ${ }^{11}$

To compare the effects of social media with those of mass media, we construct a media coverage exposure variable following Fang and Peress (2009). We collect data from the "Daily News" section of the RESSET database. This section collects public news on specific stocks from well-known media sources, including Shanghai Securities News, Securities Times, China Economic Net, Sina Finance, and Tencent Finance.

Table 1 reports summary statistics on Gubapost and media coverage. Each stock sub-forum in Guba features an average of 700 postings per month. Social media and mobile networks have become increasingly popular in China since 2012, and Gubapost has grown during this period. Gubapost reached its peak in 2015, when the Chinese stock market boom attracted a huge number of investors, leading to a surge in social media postings. Compared with social media postings, the average number of news reports for each stock is small (about 7.8 per month). Similar to Fang and Peress (2009), about $20 \%$ of stocks are not covered by mass media over a given month. In contrast, every stock has social media coverage in every month in our sample.

\section{[Table 1 about here.]}

\footnotetext{
${ }^{9}$ Defined as over 10 days of suspension in a month.

${ }^{10}$ In the Chinese stock market, a special-treatment stock is an indication of an anomaly in its financial or other position that affects the company's going-concern assumption, or indicates that it will be forced to delist in the near future.

${ }^{11}$ We list all of the variables' definitions in Table 17 in the appendix.
} 
In addition, we also test the correlation between Gubapost and firm characteristics. The result shows Gubapost is highly correlated to news coverage (the coefficient is $46 \%$ ) and shareholder bases(the coefficient is 49\%), which indicates Gubapost is related to investor recognition. It might be reasonable to assume that stocks with big size, high volatility and high return may attract more Gubapost, we find that correlation coefficient is $23 \%, 22 \%$ and $11 \%$ respectively.. Gubapost also associate with analyst coverage with the coefficient for $9 \%$. We don't report the table for brevity.

\section{Empirical results}

In this section, we investigate social media effects on cross-sectional stock returns. We first look into the average excess returns of portfolios double-sorted by firm characteristics and social media coverage, and then study the risk-adjusted returns of these portfolios.

We use a nonparametric study to examine the effects of Gubapost across famous anomalies including Size, B/M, Liquidity, Volatility, Price, Institution holding ratio, Turnover, Dollar trading volume, max daily return over the previous month $R_{\max }$, monthly return of previous month $R_{t-1}$, Gross profitability and Analyst coverage. Following Fang and Peress (2009), we double-sort stocks first by these firm characteristics and then in each group we sort stocks by Gubapost. ${ }^{12}$ Table 2 reports average one-month-ahead returns in excess of the risk-free rate for $3 \times 3$ value-weighted (VW) portfolios double-sorted by firm characteristics and Gubapost. We find that as Gubapost increases, the average return decreases. The column "L-H" reports the average returns of a long-short portfolio (long the lowest postings portfolio and short the highest postings portfolio in each size tercile), with significantly positive returns of up to $2.07 \%$ per month in the small tercile. ${ }^{13}$ The results show that the social media effect exists across different sizes of firm, except for the top quintile. Similar patterns of social media effects can be observed across other firm characteristics. The long-short portfolios with less significant

\footnotetext{
${ }^{12}$ When we single sort stocks by Gubapost, we find that the low-Gubapost portfolio has an average monthly excess return of $2.21 \%$ while high-Gubapost portfolio has only $0.67 \%$. The difference is $1.54 \%$ and is significant at the $5 \%$ level.

${ }^{13}$ The results are robust across $4 \times 4$ and $5 \times 5$ value-weighted portfolios, and $3 \times 3,4 \times 4$ and $5 \times 5$ equal-weighted portfolios. These results are not shown in table for brevity and available upon request.
} 
returns are the portfolios of stocks with big firm size, high $B / M$, high liquidity, low volatility, low turnover, and high sentiment. These stocks are likely to have more analyst coverage, more mass media coverage, and less information asymmetry, and thus better investor recognition. Accordingly, social media have limited effects on such stocks. In the same way, high returns will attract investors to focus the information about stocks, which also increase the investor recognition. Therefore, social media plays an indispensable role in providing information on less recognized stocks, and the premium of the social media effect on these stocks is significantly higher.

[Table 2 about here.]

Next, we identify the risk associated with investor recognition by constructing a Social Media Factor $(S M F)$ and examining social media effects on the cross-sectional stock returns. Similar to Fang and Peress (2009), we divide all of the sample stocks into three groups according to Gubapost and calculate the one-month-ahead value-weighted return of the portfolio of the lower 1/3 Gubapost stocks minus those of the higher $1 / 3$ as the value of $S M F^{14}$. We calculate the returns of the long-short portfolio every month to obtain a time series, which represents the risk factor of the social media effect. For purpose of comparison, we also construct a Mass Media Factor $(M M F)$ following Fang and Peress (2009). We also construct factors for the three-factor model of Fama and French (1993), four-factor model of Carhart (1997), five-factor model of Fama and French (2015), and liquidity factor (LIQ) of Pastor and Stambaugh (2003). All of the factors and their definitions are listed in Table 17. Table 3 reports the summary statistics of these factors. In our sample period, $S M F$ accounts for a risk premium of $1.54 \%$ per month, which is higher than the premiums for size $(1.45 \%)$, growth $(0.21 \%)$, and other factors. ${ }^{15}$. Penal B of Table 3 reports the correlation matrix among $S M F$ and other factors, which shows $S M F$ is highly correlated with many known factors such as $S M B$ and $H M L$. So it's important

\footnotetext{
${ }^{14}$ We construct SMF exactly the same way as "mass media effect factor" in Fang and Peress (2009) so that the results are directly comparable. In addition, we construct another "SMF2" follow the approach in Fama and French (1993) to control for firm size. The correlation of two factors is 0.96 , the empirical results on "SMF" and "SMF2" are similar. So, we only report the results for "SMF". We thank an anonymous referee for pointing this out.

${ }^{15}$ As a robustness check, we also use factors constructed from the CSMAR database and Guo et al. (2017), and obtain almost identical results.
} 
to examine whether social media effect has a significant risk-adjusted returns .

[Table 3 about here.]

To investigate whether the new $S M F$ indeed adds explanatory power to the previously established factors, we run a factor redundancy test by regressing $S M F$ on other factors, following Fama and French (2015) and Fang and Peress (2009). If SMF provides new information, then the intercept of the regression will be significant. Table 4 reports the results of regression on Fama-French's three factors, Carhart's four factors and Fama-French's five factors, respectively, in the sub-columns of column (1); we add the liquidity factor in column (2) and the mass media factor in column (3). We see from the regression on Fama-French's three factors that they are correlated with $S M F$, and more importantly, that the intercept is significantly positive, with a coefficient of 0.01 . We observe the same results for the four-factor and five-factor models with and without the liquidity factor. After controlling for market, size, book-to-market ratio, momentum, profitability, and investment factors, the significant positive intercept still exists and barely changes. These results show that Gubapost measures risk that cannot be explained by factors from the Fama-French and Carhart models. Moreover, the intercept remains significant after controlling for liquidity risk in column (2), which indicates that the social media factor cannot be explained by liquidity risk. When we add the mass media factor, we see that it has a significantly positive coefficient; the intercept drops from 0.010 to 0.009 but remains significant. ${ }^{16}$ In summary, we find that $S M B, H M L, L I Q$, and $M M F$ are significantly correlated with $S M F$, and thus $S M F$ provides new information beyond the existing well-known factors and measures a new type of risk of cross-sectional stock returns.

[Table 4 about here.]

Next, we examine the economic significance of the social media effect. We calculate the risk

\footnotetext{
${ }^{16}$ Hou et al. (2015) develop a q-factor model and show that of these factors, size, profitability, and investment cannot be explained by the Fama-French five factors in the Chinese market (Hou et al., 2019). We implement the factor redundancy test on the q-factor model, and obtain results similar to those for the Fama-French factors. We report the results in Table 15 .
} 
premium of SMF using a Fama-Macbeth two-step regression. We use the 25 Size-Gubapost portfolios as the left-hand-side (LHS) portfolios, and run time-series regressions of factor models to estimate betas for each factor. Then, in each period, we run a cross-sectional regression of portfolio returns on estimated betas to obtain the risk premium.

[Table 5 about here.]

Table 5 presents the Fama-Macbeth regression results. Column (1) reports the baseline results for the Fama-French three-factor, Carhart four-factor, and Fama-French five-factor models. We see that the $R^{2}$ of the three-factor models ranges from $49 \%$ to $66 \%$. With $S M F, R^{2}$ increases by $10-20 \%$, indicating that $S M F$ effectively explains portfolio returns. We also note that the risk premium of SMF is 0.02 and significant at the $1 \%$ level with an annualized return of about $26.8 \% .{ }^{17}$ Note that the improvement on $R^{2}$ of the mass media effect of Fang and Peress (2009) is not as high as that of $S M F$. The results suggest that the social media effect is economically significant, as it generates a high premium per unit of risk.

Our study illustrates that the social media effect's impact on asset pricing is both economically and statistically significant. We further evaluate the impact by comparing the performance of factor models with and without SMF. We use the GRS statistic of Gibbons et al. (1989). The spirit of the GRS test is to determine whether the intercepts in regressions of portfolio returns on factor returns are jointly indistinguishable from zero, which is also the key point of the asset pricing model. The null hypothesis of the GRS test is that the intercepts of regressions are jointly indistinguishable from zero. To fully capture different characteristics of portfolios, we construct three kinds of LHS portfolios according to $5 \times 5$ Size-B/M, $5 \times 5$ Size-Gubapost, and $2 \times 4 \times 4$ Size-B/M-Gubapost. We use four metrics to measure the performance of the model. The first metric $p(G R S)$ is the $p$-value of the GRS statistic. The second metric is $A\left|\alpha_{i}\right|$, the averaged absolute value of $\alpha$, which is the excess returns not explained by risk factors (see Fama and French, 2015). The third measure is the indicator of total mean absolute

\footnotetext{
${ }^{17}$ Harvey et al. (2016) argue that a new factor needs to clear a much higher hurdle, with a $t$-statistic greater than 3.0. In our model, the $t$-statistic of $\beta$ of Gubapost is about 4.0.
} 
pricing error (MAPE) measured by $|\alpha|+\frac{1}{N}|\epsilon|$ in Adrian et al. (2014). The last measure, adj. $R^{2}$, is the average adjusted $R^{2}$ of the time-series regression, which measures pricing power simultaneously. Obviously, better model performance would be indicated by larger values of $p(G R S)$ and adj. $R^{2}$ and smaller values of $A\left|\alpha_{i}\right|$ and $M A P E$. Table 6 provides the statistics of the four measures.

[Table 6 about here.]

In Table 6, column (1) reports test statistics for the Fama-French three-factor, Carhart fourfactor, and Fama-French five-factor models, and Column (2) reports the statistics for the same models augmented by $S M F$. The table shows that models with $S M F$ perform better. For instance, in the Size-Gubapost portfolios, adding SMF to the Fama-French three-factor model changes the $p$-value of the GRS statistic from 0.0060 to 0.0272 . The results suggest that $S M F$ enhances the performance of asset-pricing models and has a pricing power for cross-sectional returns. Even in Size-B/M groups, which are independent of Gubapost, SMF improves model performance to certain extent.

In summary, we demonstrate that the social media effect exists across firm characteristics; the social media factor provides new information not conveyed by traditional risk factors and generates a significant positive risk premium. Asset pricing models that include the social media factor perform better in explaining cross-sectional stock returns. We now turn to exploring the economic interpretation of the social media factor.

\section{Economic interpretation}

The social media premium may provide compensation for imperfect diversification. The investor recognition hypothesis proposed by Merton (1987) holds that in an incomplete information environment, investors only know a subset of the available stocks, so stocks with lower recognition need to provide a risk premium to compensate their holders for being imperfectly diversified. Thus, stocks with lower recognition should have a higher rate of return. In empirical studies, because "investor 
recognition" is intangible, most literatures use shareholder base as the indicator to show the investor recognition of last period (Bodnaruk and Ostberg, 2009; Zhu and Jiang, 2018). However, shareholder base is only reported quarterly, so previous studies have had to select proxy variables from different perspectives. These have included media coverage (Fang and Peress, 2009; Barber and Odean, 2008), advertising investment (Grullon et al., 2004; Chemmanur and Yan, 2010), and company name (Green and Jame, 2013). ${ }^{18}$

In our study, the key variable Gubapost measures the number of postings about a stock in Guba. In order to post something, investors must know the name or code of the stock, which ensures they have a certain degree of recognition of the stock. It is from this perspective that we argue that the number of social media postings is a direct measure of investor recognition of a stock. In addition, social media provide a convenient recognition channel with low information cost to thousands of investors. The mean and median number of readers for each post in Guba is 2,068 and 1,240, respectively, indicating that information in a post will spread to about 1,000 to 2,000 investors. Thus, a higher amount of social media postings means the information will reach more investors, thereby increasing the level of investor recognition. Recognition of a stock leads investors to take the stock into consideration in their portfolio allocation. Thus, social media postings should be positively related to the shareholder bases and other investor recognition measures.

We therefore test whether Gubapost is positively related to other proxies of investor recognition used in pervious studies, including the number and the growth of shareholders, mass media coverage and advertising cost. In China, listed companies are required to disclose the number of shareholders and other financial indicator in their quarterly reports. For every quarter, we run a cross-sectional regression of the proxies on the logarithm of Gubapost and control for firm size, firm age, share price (the inverse of median price of the company stock over the previous year), return, and volatility (the

\footnotetext{
${ }^{18}$ There are studies provide evidence not in support of Merton's investor recognition hypothesis (see Shapiro, 2002; Sun et al., 2010). We note that empirical results in Shapiro (2002) that investor recognition effect is weak not in the whole market but in big-size (visible) stocks, is consistence with our results. In addition, Shapiro (2002) uses pension fund investment as proxy of investor recognition. Sun et al. (2010) studies EREITs market which has different investor structure to that of Chinese stock market. We view these studies and our paper are complementary to gain a better understanding of Merton's hypothesis.
} 
average standard deviation of stock returns in the past three months), as in Bodnaruk and Ostberg (2009). Table 7 reports the average estimates over the sample quarters.

[Table 7 about here.]

Column (1) in Table 7 shows that there is a significant positive relationship between the number of social media postings and the number of shareholders. An increase of Gubapost by one logarithmic unit corresponds to a 0.454 logarithmic unit increase in the shareholder base. Because shareholder base is a highly persistent variable, we also test whether Gubapost has positive relationship with the change of shareholder bases. Column (2) shows Gubapost has a significant positive relationship with the change of shareholder bases. An increase of Gubapost by one logarithmic unit will bring $3.1 \%$ increase in total shareholder base. In addition, we use media coverage of Fang and Peress (2009) and Barber and Odean (2008), advertising investment of Grullon et al. (2004) and Chemmanur and Yan (2010) as proxies of investor recognition. Again, we find significant positive relationships in Column (3) and (4). These results show that Gubapost is positively related to conventional proxies of investor recognition.

In addition, there are some advantages of Gubapost measure over other measurements of investor recognition. First, media coverage and advertising investment are based on information dissemination and it can't be sure that investors receive the information and recognize the stock. While Gubapost is a direct measure that investors must have a certain recognition of a stock before they post on Gubaforum. Second, shareholder base of a stock reflects the number of investors who have taken the stock in their portfolios. However, it ignores potential investors who have recognition of the stock and may add it to their portfolios in the future. Gubapost reflects stock recognition of both current and future investors. Third, it is easy to get both historical and live data of Gubapost and it is not subject to restrictions of quarterly disclosure suffered by other measures.

We argue that social media postings broaden investor recognition and increase the shareholder base. However, stocks with a large shareholder base may garner more postings on social media, which may 
introduce an endogenous issue. Therefore, we double-sort stocks by shareholder base and Gubapost into $2 \times 2$ sub-samples, and run the preceding regression for each sub-sample. Table 8 reports the results $^{19}$.

[Table 8 about here.]

In each sub-sample in Table 8, there is still a significantly positive relationship between the number of social media postings and the number of shareholders. It is worth noting that in columns (2) and (3), for the sub-sample of high shareholder base and low Gubapost and the sub-sample of low shareholder base and high Gubapost), the relationship is still significant, which suggests that the positive relationship is robust across sub-samples double-sorted by shareholder base and Gubapost. This lends further support for the argument that Gubapost is a good proxy for investor recognition.

In the literature, there are other interpretations of the social media effect. Kim and Kim (2014) interpret the social media effect on cross-sectional returns in terms of sentiment. To evaluate the possible sentiment effect in Gubapost, we classify Gubapost into three groups (positive, neutral, and negative) using a Naive Bayesian Classification method of textual analysis (see Kim and Kim, 2014; Leung and Ton, 2015). ${ }^{20}$ We classify 149,569,708 postings; the highest proportion are neutral in sentiment (about 74.8\%), while negative postings account for $16.6 \%$ and positive for $8.6 \%$. If the social media effect is related more closely to recognition than sentiment, we should observe the social media premium across positive, negative, and neutral sentiment. Similar to Table 2, we report average one-month-ahead returns in excess of the risk-free rate for 25 value-weighted portfolios double-sorted by Size and Gubapost under different sentiments in Table 9.

\footnotetext{
${ }^{19}$ We also report regression results in Table 7 using other proxies of investor recognition as dependent variables, we find consistent results. These results are available upon request.

${ }^{20}$ Details of the classification method are provided in the appendix. Feng et al. (2015) check the accuracy of the classification and find that the in-sample accuracy reaches $85.4 \%$. They randomly choose and manually classify another 1,000 messages for an out-of-sample test. The accuracy rate of the out-of-sample test is also high, at $77.9 \%$. This result is better than that in prior studies of English classification (e.g. Das and Chen, 2007; Kim and Kim, 2014). More importantly, the number of messages classified as the opposite sentiment (positive messages classified as negative and vice versa) is low $(0.4 \%$ and $0.2 \%)$, which suggests a low level of systematic error.
} 
[Table 9 about here.]

The results in Table 9 indicate that a social media premium exists across different sentiment groups. Panel B of Table 9 shows that the premium of sentiment-neutral social media postings has a similar pattern to that of the whole sample of social media in Table 2. In each panel, there is a similar pattern: as Gubapost increases, the average return of the stock portfolio has a significant decrease. That is, as long as the postings increase, no matter how the sentiment changes, the corresponding investor recognition will increase and the premium will decrease. The results suggest that rather than sentiment, the social media effect is induced by investor recognition.

We also investigate other sentiment proxies, for example Turnover(Baker et al., 2012), Dollar trading volume(Scheinkman and Xiong, 2003; Baker et al., 2012), and max daily return in the past months (the MAX effect) (Bali et al., 2011; Fong and Toh, 2014). They find that past high sentiment (high turnover, volume and $R_{\max }$ ) results in an overestimation of stock price, which leads to a low return in the following month. We further test this to see if the social media effect can be subsumed by the sentiment effect. We construct TurnoverF from the return of a portfolio of $1 / 3$ low turnover stocks minus the return of a portfolio of $1 / 3$ high turnover stocks. We construct VolumeF and MAXF similarly. We regress $S M F$ on these sentiment factors to see if it produces a significant positive $\alpha$, and control for commonly used factors.

[Table 10 about here.]

Table 10 reports the regression results. In each column, we control for $M M F$ and $L I Q$ and other commonly used factors, as in Column (3) of Table 4. The results indicate that the sentiment effect is positively associated with the social media effect. We observe a positive correlation between VolumeF and $S M F .^{21}$ Overall, we see that the intercepts of the regressions are all significantly positive, which

\footnotetext{
${ }^{21}$ Due to multicollinearity with VolumeF, TurnoverF and $M A X F$ show little or no correlation with $S M F$. Further tests find that each single sentiment proxy has a significant positive correlation with $S M F$. We note that the multicollinearity has little impact on the significance of the intercept; the results are available upon request.
} 
indicates that the social media effect cannot be subsumed by the sentiment effect. ${ }^{22}$

In summary, we find that Gubapost is positively related to the number of shareholders, and the relationship is robust across sub-samples double-sorted by number of shareholders and Gubapost. We also find that the social media effect cannot be subsumed by the sentiment effect, which supports the view that Gubapost is a measure of investor recognition rather than a measure of sentiment. We therefore conclude that Gubapost is a better measure of investor recognition than others proposed in the literature; thus, this paper provides the first direct support for Merton's investor recognition hypothesis.

\section{Profitability}

We find that stocks with low social media postings earn a return premium. Here, we examine the out-of-sample profitability of portfolios of long stocks with low social media postings and short stocks with high social media postings. We develop decile portfolios on social media postings and obtain the one-month-ahead value-weighted returns of these portfolios. The monthly performance of the portfolios is reported in Table 11.

[Table 11 about here.]

Column (1) of Table 11 reports one-month-ahead value-weighted excess returns (to the risk-free rate) of each portfolio. The portfolio of the lowest $10 \%$ of Gubapost has an average monthly excess return of $2.6 \%$. As the postings increase, the excess returns of the portfolios decrease. ${ }^{23}$ The difference of returns between the lowest $1 / 10$ and highest $1 / 10$ Gubapost is $2.4 \%$ per month and it is significant. In addition, we compare the results with the returns of portfolios grouped by tercile, and the long-short

\footnotetext{
${ }^{22}$ Some researches document that VolumeF and TurnoverF are also the measures of investor disagreement (see Miller, 1977; Hong and Stein, 2007). So our results also indicate that social media effect cannot be subsumed by the disagreement effect.

${ }^{23}$ Note that there is no monotonic decrease around D7; however, the p-value of difference D7-D6 is 0.33, far from significant, while those of D1-D7 and D7-D10 are significant, which indicates that the nonlinear trend around D7 is caused by outliers.
} 
portfolios still have a significant return of about $1.5 \%$. Controlling for three, four, five and liquidity factors, we report the risk-adjusted return and intercept (alpha) in Columns (2)-(5). The alphas are consistently positive, and are both economically and statistically different from zero for most portfolios. The alphas range between 1.3\% (the lowest postings portfolio in Column (5)) and $-0.36 \%$ (the highest postings portfolio in Column (5)) with a premium of 1.66\%. Column (6) of Table 11 reports the winning ratio of the portfolios' outperformance of the VW market portfolio, indicating that in $70 \%$ of the months in our sample, the long position of the portfolio with the lowest level of social media postings can outperform the market portfolio. The winning ratio for the long-short portfolio is $63 \%$, which indicates that in most cases, the long-short portfolio outperforms the market portfolio. The last two columns reflect the risk of the portfolio, i.e., the standard deviation and Sharpe ratio of the portfolios.

We further examine whether this profitability can be sustained across different sub-samples of firm characteristics. We build the portfolio by taking a long position on the lowest $10 \%$ and a short position on the highest $10 \%$ of Gubapost. ${ }^{24}$ We use firm Size, Book - to - Market ratio, and Momentum as the characteristics of the firms, and sort them into three sub-samples. In each sub-sample, we report the portfolio's abnormal returns (alpha) as estimated by different factor models.

[Table 12 about here.]

Table 12 reports the significant risk-adjusted returns of the long-short strategy across sub-samples of different firm characteristics. We note that Fang and Peress (2009) tests the illiquidity hypothesis for the media coverage effect. The illiquidity hypothesis holds that the effect reflects mispricing and can be eliminated by arbitrage trading. Similarly, we examine whether the social media effect supports the illiquidity hypothesis. If the abnormal returns are concentrated among the most illiquid stocks, the social media effect can be eliminated by arbitrage, which supports the illiquidity hypothesis. We

\footnotetext{
${ }^{24}$ In terms of investability, the portfolio has an average stock number of 400, 200 for the long position and 200 for the short position. The small number of stocks is easy to manage and rebalance. The long-short portfolio also ensures initial zero investment.
} 
use long stocks with the lowest $10 \%$ of Gubapost and short stocks with the highest $10 \%$. We use Amihud's Illiquidity Ratio and Dollar Trading Volume as proxies for illiquidity. We examine the risk-adjusted returns of the portfolios in samples sorted by these measures. Panels A and B of Table 13 report the risk-adjusted returns of portfolios under different factor models. The reported alphas are significantly positive among all illiquidity sub-samples. For example, the alphas range from $1.2 \%$ to $1.7 \%$ in the first column of Panel A, which indicates that there is not enough evidence to support the illiquidity hypothesis.

We also examine the impacts of the sentiment effects on the profitability of the social media effect trading strategy. As before, we sort stocks according to sentiment proxies such as Turnover, $R_{\text {max }}$, and Dollar Trading Volume. (see Scheinkman and Xiong, 2003; Baker et al., 2012; Bali et al., 2011; Fong and Toh, 2014). Panels B and C of Table 13 report the risk-adjusted returns of portfolios under different factor models. The significantly positive alphas indicate that the excess returns of the long-short social media effect strategy cannot be explained by the sentiment effect.

[Table 13 about here.]

We also develop two trading strategies to test whether the profitability driven by the social media premium is persistent. The first is a buy-and-hold strategy to long stocks with the lowest $10 \%$ of social media postings. The second strategy holds a zero-investment portfolio and uses a long-short strategy, that is, to long stocks in the lowest decile of Gubapost and to short the highest decile. We rebalance the two portfolios monthly according to updated Gubapost. Figure 1 shows the cumulative returns of the two strategies compared with the VW market portfolio.

[Figure 1 about here.]

We see from Figure 1 that the two strategies achieve returns of about $300 \%$ for the whole sample period. Despite drawdowns, they appear to outperform the market portfolio. Next, we expand the portfolio holding period to 12 months. Table 14 reports the annual returns of the two strategies. Table 
14 shows that the buy-and-hold strategy can achieve nearly $40 \%$ annualized return and $22.6 \%$ factorfree excess return with a winning ratio of $90 \%$ against the VW market portfolio. In addition, we use three market indices as benchmark to evaluate portfolio performance, that is CSI 300 (300 companies with biggest size), CSI 500 (500 companies with medium size) and CSI 1000 (1000 companies with small size). The long only strategy have excess returns of $27.3 \%, 19.5 \%, 12.9 \%$ respectively. For the long-short strategy, the annualized return is about $32 \%$, and the Sharpe ratio is 1.168.

[Table 14 about here.]

Overall, the performance of the two strategies shows that portfolios constructed by the social media premium are able to generate economically significant profits. Portfolio managers and market practitioners should therefore take the social media premium into account in their portfolio and risk management.

\section{Conclusion}

Previous studies of the social media effect on asset pricing have mainly been undertaken in relation to the time series effect and sentiment effect. This paper focuses on the social media effect on crosssectional stock returns. Using Gubapost as a measure of social media coverage of the Chinese stock market, we find a significant social media premium. We further identify the risk associated with investor recognition by constructing a social media factor based on the social media premium, and find that the social media factor provides new information not covered by the well-known Fama-French factors and the mass media factor of Fang and Peress (2009), and this factor cannot be subsumed by sentiment effects. Fama-French factor models augmented by the social media factor are able to generate significant risk-adjusted returns. The risk pricing test finds that per unit of risk, the social media effect can bring about a $2 \%$ change in returns of market portfolios. The GRS statistics also show that the social media factor enhances the performance of existing factor models. 
Why the social media factor can improve the explanation power of cross-sectional asset returns of the well-known Fama-French factor models? We show that the mechanism is the risk associated with investor recognition. In informationally incomplete markets, investors have limited recognition of all stocks, their portfolios are imperfectly diversified, and they need to be compensated for holding such portfolios. We find that the number of social media postings is a better measure of investor recognition than existing ones in the literature. Therefore, this paper provides direct evidence in support of the investor recognition hypothesis of Merton (1987). Furthermore, we find that trading strategies based on social media premium can produce a sizable profit, which suggests that market practitioners should take the social media effect into account in their portfolio and risk management.

\section{Appendices}

\section{A. The textual analysis process}

To obtain data on the sentiment of posts collected from Guba, we classify them into three types according to their sentiment: positive, neutral, and negative. Naive Bayesian Classification is used for textual analysis. Naive Bayesian Classification is a simple and efficient method widely used for sentiment classification (Antweiler and Frank, 2004; Feng et al., 2015). We follow the method from the aforementioned papers, using the Chinese sentiment dictionary of Feng et al. (2015) based on FudanNLP, the HowNet Chinese sentiment dictionary, and 1,043 special online terms that are considered

Key Sentiment Words on Chinese stock message boards. Five thousand training sentences are chosen and manually classified into three groups as the training sample.

Naive Bayesian Classification assumes that the occurrences of words are independent of each other. The conditional probability that one message contains the keyword $W_{I}$, which is included in Key Sentiment Words belongs to the sentiment group $T_{C}, C \in\{$ Positive, Neutral, Negative $\}$, is as follows: 


$$
P\left(T_{C} \mid W_{I}\right)=\frac{P\left(W_{I} \mid T_{C}\right) P\left(T_{C}\right)}{P\left(W_{I}\right)}=\frac{P\left(T_{C}\right) \sum_{k=1}^{I} P\left(w_{k} \mid T_{C}\right)}{\sum_{k=1}^{I} P\left(w_{k}\right)}
$$

where $w_{k}$ is a word from the sequence $W_{I}$, and $I$ is the total of $W_{I}$. We can calculate the sentiment probability of each message and choose the one with the maximum probability as its sentiment type and set its value to $\{-1,0,1\}$.

$$
\text { Type }\left(W_{I}\right)=\operatorname{Max}\left\{P\left(T_{c} \mid W_{I}\right)\right\}, \quad C \in\{\text { Positive, Neutral, Negative }\}
$$

where:

$$
\text { Sentiment }_{I}=\left\{\begin{array}{cc}
1 & W_{I}=\text { Positive } \\
0 & W_{I}=\text { Neutral } \\
-1 & W_{I}=\text { Negative }
\end{array}\right.
$$

\section{B. The redundancy test for q-factors}

Retail investors are highly responsive to earnings and investment decisions. Firm profitability and investment are thus powerful ex post explanatory variables in cross-sectional returns. However, the profitability and investment factors in Fama and French (2015) seem to have limited explanatory power for the Chinese stock market (Guo et al., 2017). Hou et al. (2015) develop a q-factor model, and find that the size, profitability, and investment factors among the q-factors cannot be explained by the Fama-French five factors (Hou et al., 2019). Their model thus provides a better explanation of the cross-sectional returns of the Chinese stock market.

We implement the redundancy test on the q-factors constructed from Hou et al. (2015), and report the results in Table 15. We see that the q-factors have little correlation with $S M F$ except the q-size factor. In Columns (1) and (2) the q-size factor has a positive relationship with $S M F$, while other 
q-factors contribute little to explaining $S M F$. However, the relationship disappears after controlling for $M M F$. It is worth noting that the intercepts of the regressions remain significantly positive, which indicates that the q-factors cannot perfectly explain the social media effect. Overall, the results for the q-factors are similar to those for the Fama-French factors, showing that the investor recognition effects reflected by the social media factor cannot be subsumed by the usual factors in the literature on cross-sectional stock returns.

[Table 15 about here.]

\section{Parsimonious model and short-term reversal factor.}

Short-term reversal effect is an important anomaly in financial market, which has been reported in Chinese market (Nusret et al., 2017; Han et al., 2019). Pervious literature shows that the short-term reversal effect is related to overreaction, fads, or simply cognitive errors as well as price pressure when the short-term demand and supply curve changing(Da et al., 2011; Jegadeesh and Titman, 1993). Stock with high return may attract more discussion in social media, so it's reasonable doubt that low

Gubapost comes from the low returns of the stock in the prior month, which leads to high returns in the subsequent month. In order to examine whether social media effect can be explained by shortterm reversal effect, we construct short-term reversal factor(STREV) following Jegadeesh and Titman (1993) and Han et al. (2019), and we implement a redundancy regression on SMF.

[Table 16 about here.]

Table 16 shows the regression result, and Column (1) shows a negative relationship between $S M F$ and STREV. In other words, Gubapost and return is not absolute correlation, higher return may not be able to attract more investor posts. The result also suggests that investor recognition is a longterm process that is not dominated by the influence of short-term returns. Further, intercepts of the 
regressions remain significantly positive, which indicates that the short-term reversal effect cannot explain the social media effect.

In Column (2) of Table 16, we employ three kinds of parsimonious factor model to check the robustness of regression. The inspirit of parsimonious factor model is to explain data with a minimum number of variables. Hence, we construct the model in three ways: models (1) include the significant

factors in pervious regression; (2) exclude the factors seem not being priced in Chinese market ${ }^{25}$; (3) factors in (2) and add mass media factor and liquidity factor. The result shows in each model of redundant test, intercepts remain significant, which indicates the result is robust.

\section{Variable Definitions}

[Table 17 about here.]

${ }^{25} \mathrm{CMA}$ and UMD have little effect in China following Guo et al. (2017) 
Adrian, T., Etula, E. and Muir, T. (2014), 'Financial Intermediaries and the Cross-Section of Asset Returns', The Journal of Finance 69(6), 2557-2596.

Allcott, H. and Gentzkow, M. (2017), 'Social media and fake news in the 2016 election', Journal of Economic Perspectives 31, 211-236.

Aman, H., Kasuga, N. and Moriyasu, H. (2018), 'Mass media effects on trading activities: television broadcasting evidence from Japan', Applied Economics 0(0), 1-18.

Antweiler, W. and Frank, M. Z. (2004), 'Is All That Talk Just Noise? The Information Content of Internet Stock Message Boards', The Journal of Finance 59(3), 1259-1294.

Baker, M. and Wurgler, J. and Yuan, Y. (2012), 'Global, local, and contagious investor sentiment', Journal of Financial Economics 104(2), 272-287.

Bali, T. G. and Cakici, N. and Whitelaw, R. F (2011), 'Maxing out: Stocks as lotteries and the cross-section of expected returns', Journal of Financial Economics 99(2), 427-446.

Barber, B. M. and Odean, T. (2008), 'All That Glitters: The Effect of Attention and News on the Buying Behavior of Individual and Institutional Investors', Review of Financial Studies 21(2), 785818.

Bodnaruk, A. and Ostberg, P. (2009), 'Does investor recognition predict returns?', Journal of Financial Economics 91(2), 208-226.

Bollen, J., Mao, H. and Zeng, X. (2011), 'Twitter mood predicts the stock market', Journal of Computational Science $\mathbf{2}(1), 1-8$.

Carhart, M. (1997), 'On persistence in mutual fund performance', The Journal of Finance 52(1), 5782.

Chemmanur, T. J. and Yan, A. (2010), 'Advertising, Investor Recognition, and Stock Returns', SSRN Electronic Journal .

Da, Z., Liu, Q. and Schaumburg, E. (2011), 'Decomposing Short-Term Return Reversal', SSRN Electronic Journal.

Das, S. R. and Chen, M. Y. (2007), 'Yahoo! for Amazon: Sentiment Extraction from Small Talk on the Web', Management Science 53(9), 1375-1388.

Fama, E. F. and French, K. R. (1993), 'Common risk factors in the returns on stocks and bonds', Journal of Financial Economics 33(1), 3 - 56.

Fama, E. F. and French, K. R. (2015), 'A five-factor asset pricing model', Journal of Financial Economics 116(1), 1-22.

Fang, L. and Peress, J. (2009), 'Media Coverage and the Cross-section of Stock Returns', The Journal of Finance 64(5), 2023-2052.

Feng, X., He, X.-Z., Lin, S. and Wang, J. (2015), 'Online Sentiment Contagion in China ', working paper pp. 1-47.

Ferguson, N. J., Philip, D., Lam, H. Y. and Guo, J. M. (2015), 'Media Content and Stock Returns: The Predictive Power of Press', Multinational Finace Journal 19(1), 1-31.

Fong, W. M. and Toh, B. (2014), 'MAX, Lottery-like stocks, Investor sentiment, Investor optimism, Market efficiency', Journal of Banking \& Finance 46(C) 190-201.

Gibbons, M. R., Ross, S. A. and Shanken, J. (1989), 'A Test of the Efficiency of a Given Portfolio', Econometrica 57(5), 1121. 
Green, T. C. and Jame, R. (2013), 'Company name fluency, investor recognition, and firm value', Journal of Financial Economics 109(3), 813-834.

Griffin, J. M., Hirschey, N. H. and Kelly, P. J. (2011), 'How important is the financial media in global markets?', The Review of Financial Studies 24(12), 3941-3992.

Grullon, G., Kanatas, G. and Weston, J. P. (2004), 'Advertising, Breadth of Ownership, and Liquidity', Review of Financial Studies 17(2), 439-461.

Guo, B., Zhang, W., Zhang, Y. and Zhang, H. (2017), 'The five-factor asset pricing model tests for the Chinese stock market', Pacific-Basin Finance Journal 43(C), 84-106.

Han, X. Li, K. and Li, Y. (2019), 'Investor Overconfidence and the Security Market Line: New Evidence from China', SSRN Electronic Journal

Han, X. and Li, Y. (2017), 'Can investor sentiment be a momentum time-series predictor? Evidence from China', Journal of Empirical Finance 42, 212-239.

Harvey, C. R., Liu, Y. and Zhu, H. (2016), '… and the cross-section of expected returns', The Review of Financial Studies 29(1), 5-68.

Hirshleifer, D. (2001), 'Investor Psychology and Asset Pricing', The Journal of Finance 56(4), 15331597.

Hong, H. and Stein, J. D. (2007), 'Disagreement and the Stock Market', Journal of Economic Perspectives $\mathbf{2 1}(2), 109-128$.

Hou, K., Mo, H., Xue, C. and Zhang, L. (2019), 'Which factors?', Review of Finance 23(1), 1-35.

Hou, K., Xue, C. and Zhang, L. (2015), 'Digesting anomalies: An investment approach', The Review of Financial Studies 28(3), 650-705.

Jegadeesh, N. and Titman, S. (1993), 'Returns to Buying Winners and Selling Losers: Implications for Stock Market Efficiency', The Journal of Finance 48(1), 65-91.

Kim, S.-H. and Kim, D. (2014), 'Investor sentiment from internet message postings and the predictability of stock returns', Journal of Economic Behavior $\&$ Organization 107, 708-729.

Lazer, D., Baum, M. A., Benkler, Y., Berinsky, A. J., Greenhill, K. M., Menczer, F., Metzger, M. J., Nyhan, B., Pennycook, G. and Rothschild, D. (2018), 'The science of fake news.', Science 359(6380), 1094-1096.

Lee, J. M., Hwang, B. H. and Chen, H. (2016), 'Are founder ceos more overconfident than professional ceos? evidence from s\&p 1500 companies', Strategic Management Journal 38(3), 751-769.

Leung, H. and Ton, T. (2015), 'The impact of internet stock message boards on cross-sectional returns of small-capitalization stocks', Journal of Banking $\mathcal{E} 3$ Finance 55(C) 37-55.

Merton, R. C. (1987), 'A Simple Model of Capital Market Equilibrium with Incomplete Information', The Journal of Finance 42(3), 483-510.

Miller, E. M. (1977), 'Risk, Uncertainty, and Divergence of Opinion', The Journal of Finance 32(4), 1151-1168.

Miller, G. S. and Skinner, D. J. (2015), 'The Evolving Disclosure Landscape: How Changes in Technology, the Media, and Capital Markets Are Affecting Disclosure', Journal of Accounting Research 53(2), 221-239.

Nusret, C., Kalok, C. and Kudret, T. (2017), 'Cross-sectional stock return predictability in China', The European Journal of Finance 23, 581-605. 
Pastor, L. and Stambaugh, R. (2003), 'Liquidity risk and expected stock returns', Journal of Political Economy 111(3), 642-685.

Scheinkman, J. A. and Xiong, W. (2003), 'Overconfidence and Speculative Bubbles', Journal of Political Economy 111(6), 1183-1220.

Shapiro, A.(2002), 'The Investor Recognition Hypothesis in a Dynamic General Equilibrium: Theory and Evidence', Review of Financial Studies 15(1), 97-141.

Sprenger, T. O., Sandner, P. G., Tumasjan, A. and Welpe, I. M. (2014), 'News or Noise? Using Twitter to Identify and Understand Company-specific News Flow', Journal of Business Finance \&5 Accounting 41(7-8), 791-830.

Sun, Q., Yung, K. and Rahman, H.(2010), 'Investor recognition and expected returns of EREITs', Journal of Real Estate Portfolio Management 16(2), 153-169.

Tumarkin, R. and Whitelaw, R. F. (2001), 'News or Noise? Internet Postings and Stock Prices', Financial Analysts Journal 57(3), 41-51.

Turner, J., Ye, Q. and Walker, C. (2018), 'Media Coverage and Stock Returns on the London Stock Exchange, 1825-70', Review of Finance 22(4), 1605-1629.

Xu, Y. and Green, C. J. (2012), 'Asset pricing with investor sentiment: evidence from Chinese stock markets', The Manchester School 81(1), 1-32.

Zhu, H. and Jiang, L. (2018), 'Investor recognition and stock returns: evidence from China', China Finance Review International, 8(2) 199-215.

Zou, L., Cao, K. D. and Wang, Y. (2018), 'Media coverage and the cross-section of stock returns: The Chinese evidence', International Review of Finance, $\mathbf{0}(0)$ 1-23. 


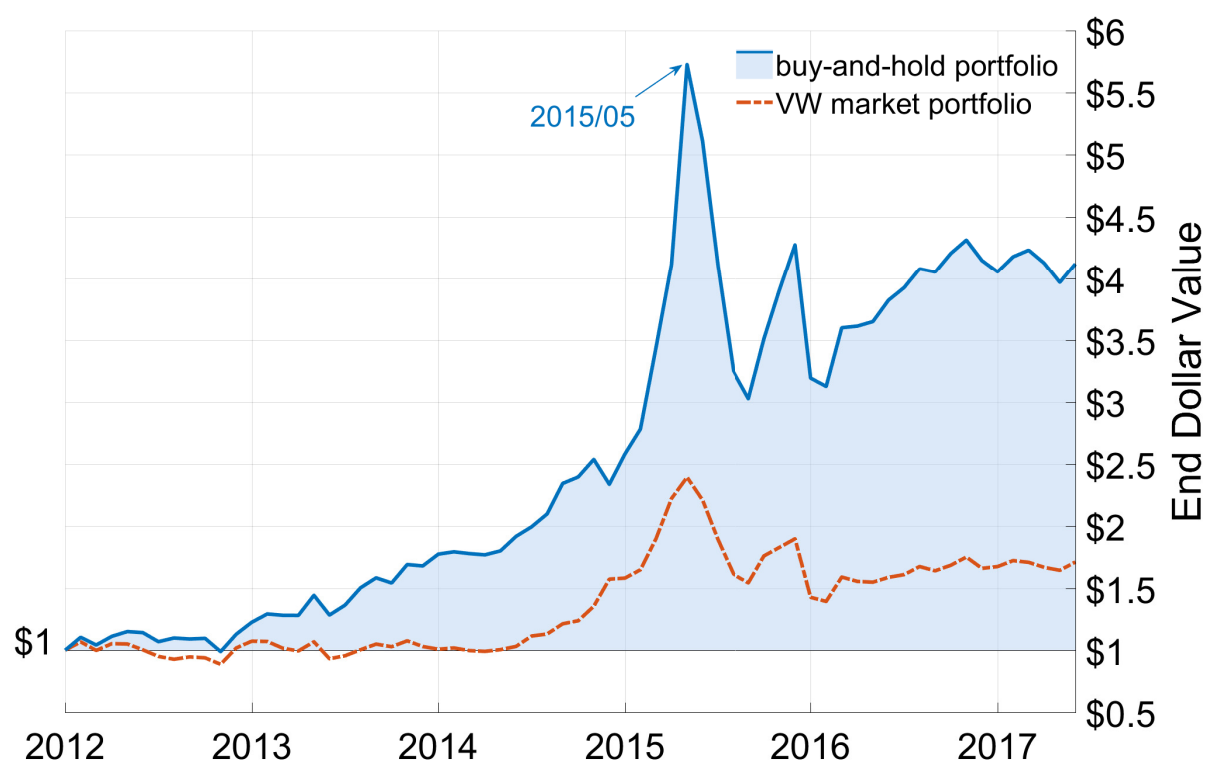

(a) Buy-and-Hold Strategy

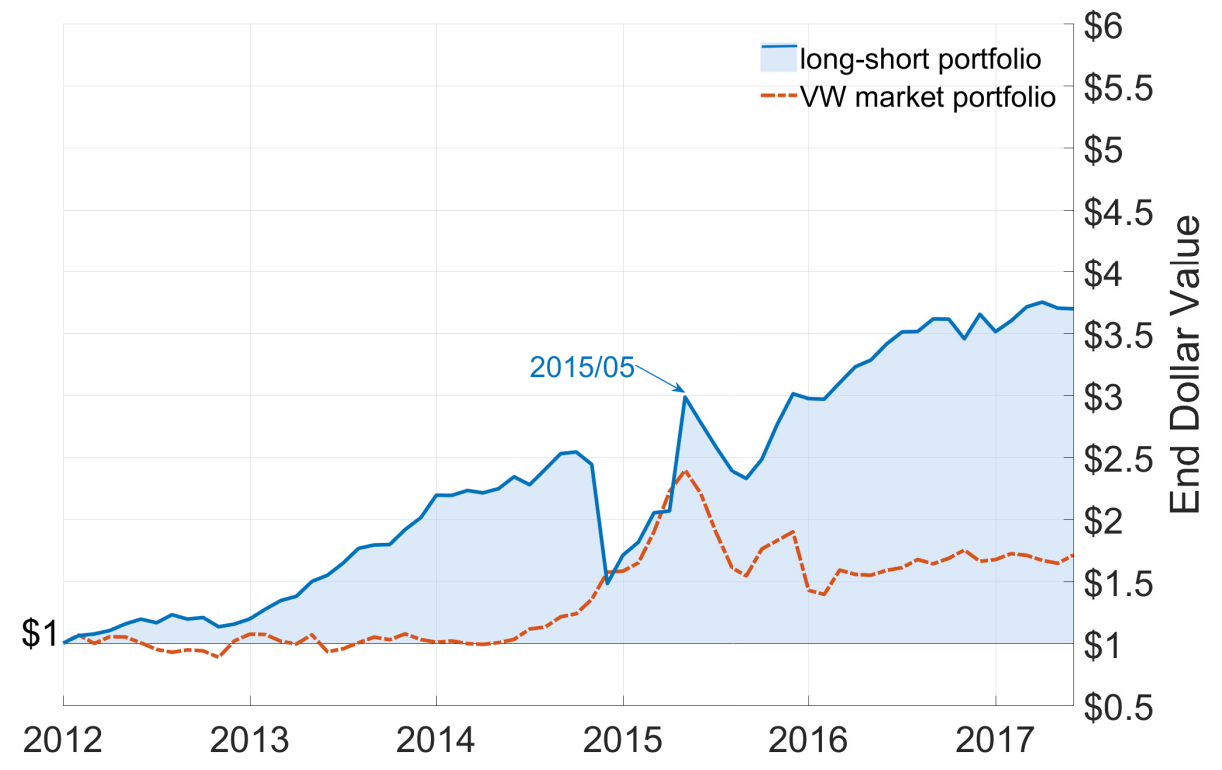

(b) Long-Short Strategy

Figure 1: Cumulative returns of strategies

This figure shows the cumulative returns of strategies with an initial investment of $\$ 1$. There are two strategies shown: (a) the buy-and-hold strategy, which holds a long position on the lowest $10 \%$ of Gubapost for one month; (b) the long-short strategy, which holds a long position on the lowest $10 \%$ and a short position on the highest $10 \%$ of Gubapost. The blue shaded area represents the returns of the strategy, while the orange dashed line is the base returns of the value-weighted market portfolio. 
Table 1: Summary statistics of social media and mass media coverage during 2012.1-2017.6

This table reports summary statistics for Gubapost and mass media coverage. The summary statistics include the average, standard deviation, minimum, percentile of $5 \%$ to $95 \%$, maximum and minimum of Gubapost, and mass media coverage. The row "overall" reports the corresponding statistics for the full sample period.

\begin{tabular}{|c|c|c|c|c|c|c|c|c|c|}
\hline Period & Mean & $\overline{\overline{\text { Std }}}$ & Min & P5 & $\mathrm{P} 25$ & Median & P75 & P95 & Max \\
\hline \multicolumn{10}{|l|}{ Panel A: Gubapost } \\
\hline 2012.1 2012.6 & 492.8 & 843.8 & 11 & 61 & 154 & 293 & 551 & 1459 & 22867 \\
\hline $2012.7 \sim 2012.12$ & 370.5 & 592.2 & 10 & 49 & 115 & 216 & 410 & 1138 & 17655 \\
\hline 2013.1 2013.6 & 439.9 & 677.5 & 7 & 60 & 144 & 260 & 487 & 1276 & 14440 \\
\hline 2013.7〜2013.12 & 598.7 & 909.1 & 13 & 87 & 203 & 363 & 660 & 1825 & 34041 \\
\hline $2014.1 \sim 2014.6$ & 426.2 & 547.8 & 12 & 64 & 149 & 270 & 490 & 1296 & 10653 \\
\hline $2014.7 \sim 2014.12$ & 753.4 & 1018.2 & 1 & 96 & 249 & 464 & 876 & 2277 & 30154 \\
\hline $2015.1 \sim 2015.6$ & 1289.6 & 2403.2 & 1 & 129 & 343 & 694 & 1410 & 4156 & 135392 \\
\hline $2015.7 \sim 2015.12$ & 1002.0 & 1385.9 & 1 & 136 & 327 & 618 & 1150 & 3052 & 37582 \\
\hline 2016.1 2016.6 & 738.9 & 859.8 & 1 & 124 & 289 & 494 & 875 & 2087 & 18907 \\
\hline $2016.7 \sim 2016.12$ & 737.9 & 1278.1 & 1 & 110 & 271 & 480 & 842 & 2094 & 89106 \\
\hline 2017.1 2017.6 & 623.3 & 801.6 & 1 & 98 & 229 & 400 & 705 & 1844 & 14676 \\
\hline overall & 700.7 & 1186.7 & 1 & 82 & 214 & 406 & 784 & 2175 & 135392 \\
\hline \multicolumn{10}{|l|}{ Panel B: News } \\
\hline 2012.1 2012.6 & 3.6 & 6.8 & 0 & 0 & 0 & 2 & 4 & 14 & 110 \\
\hline 2012.7〜2012.12 & 3.6 & 7.4 & 0 & 0 & 0 & 1 & 4 & 14 & 195 \\
\hline 2013.1 2013.6 & 4.1 & 8.3 & 0 & 0 & 0 & 2 & 5 & 15 & 190 \\
\hline 2013.7〜2013.12 & 6.6 & 12.4 & 0 & 0 & 1 & 3 & 8 & 23 & 517 \\
\hline $2014.1 \sim 2014.6$ & 5.9 & 11.2 & 0 & 0 & 1 & 3 & 7 & 20 & 215 \\
\hline $2014.7 \sim 2014.12$ & 6.8 & 12.0 & 0 & 0 & 1 & 3 & 8 & 23 & 200 \\
\hline $2015.1 \sim 2015.6$ & 6.7 & 12.3 & 0 & 0 & 1 & 3 & 8 & 23 & 359 \\
\hline 2015.7〜2015.12 & 10.9 & 21.5 & 0 & 0 & 2 & 5 & 12 & 40 & 603 \\
\hline $2016.1 \sim 2016.6$ & 14.2 & 18.0 & 0 & 1 & 4 & 9 & 18 & 46 & 598 \\
\hline 2016.7 2016.12 & 12.4 & 25.0 & 0 & 0 & 3 & 7 & 14 & 41 & 1395 \\
\hline $2017.1 \sim 2017.6$ & 4.1 & 8.4 & 0 & 0 & 1 & 2 & 5 & 15 & 193 \\
\hline overall & 7.8 & 15.8 & 0 & 0 & 1 & 3 & 9 & 29 & 1395 \\
\hline
\end{tabular}


Table 2: Monthly excess returns of $(3 \times 3)$ VW portfolios.

This table reports the average monthly returns in excess of the risk-free rate for $3 \times 3$ value-weighted portfolios double-sorted by firm characteristics and Gubapost. Taking the Size $\times$ Gubapost portfolio for an example, at the beginning of each month stocks are allocated to three Size groups (Small to Big) according to their market caps, then in each size group the stocks are allocated equally to Gubapost groups (Low to High) based on the previous month's Gubapost. The intersections of the two sorts produce twelve value-weight Size-Gubapost portfolios. The row "Small" reports monthly excess returns of small firms across low, medium, and high Gubapost groups, and the column "L-H" reports the difference between high and low Gubapost portfolios of small firms. The table reports Size, B/M, Liquidity, Volatility, Price, Institutional holding ratio, Turnover, Dollar trading volume, max daily return over the past month $R_{\max }$, monthly return of pervious month $R_{t-1}$, Gross profitability and Analyst coverage. ${ }^{*},{ }^{* *}$, and ${ }^{* * *}$ indicate statistical significance at the $10 \%, 5 \%$, and $1 \%$ levels, respectively.

\begin{tabular}{|c|c|c|c|c|c|c|c|c|c|}
\hline \multicolumn{5}{|c|}{ Gubapost } & \multicolumn{5}{|c|}{ Gubapost } \\
\hline Factors & Low & Medium & High & L-H & Factors & Low & Medium & High & L-H \\
\hline \multicolumn{5}{|c|}{ Size $\times$ Gubapost portfolio } & \multicolumn{5}{|c|}{$B / M \times$ Gubapost portfolio } \\
\hline Small & 0.0361 & 0.0277 & 0.0154 & $0.0207^{* * *}$ & Low & 0.0214 & 0.0130 & 0.0015 & $0.0199^{* * *}$ \\
\hline Medium & 0.0260 & 0.0178 & 0.0085 & $0.0175^{* * *}$ & Medium & 0.0251 & 0.0142 & 0.0070 & $0.0182^{* * *}$ \\
\hline Big & 0.0147 & 0.0141 & 0.0059 & 0.0087 & High & 0.0211 & 0.0169 & 0.0085 & $0.0126^{*}$ \\
\hline \multicolumn{5}{|c|}{ Liquidity $\times$ Gubapost portfolio } & \multicolumn{5}{|c|}{ Volatility $\times$ Gubapost portfolio } \\
\hline Low & 0.0289 & 0.0278 & 0.0196 & $0.0093^{* * *}$ & Low & 0.0218 & 0.0183 & 0.0096 & $0.0121^{*}$ \\
\hline Medium & 0.0197 & 0.0170 & 0.0135 & $0.0063^{* *}$ & Medium & 0.0236 & 0.0137 & 0.0072 & $0.0164^{* *}$ \\
\hline High & 0.0146 & 0.0112 & 0.0046 & $0.0100^{*}$ & High & 0.0241 & 0.0091 & -0.0034 & $0.0274^{* * *}$ \\
\hline \multicolumn{5}{|c|}{ Price $\times$ Gubapost portfolio } & \multicolumn{5}{|c|}{ Institution holding $\times$ Gubapost portfolio } \\
\hline Low & 0.0230 & 0.0192 & 0.0077 & $0.0152^{* *}$ & Less & 0.0267 & 0.0177 & 0.0094 & $0.0173^{* *}$ \\
\hline Medium & 0.0232 & 0.0136 & 0.0082 & $0.0150^{* *}$ & Medium & 0.0207 & 0.0163 & 0.0106 & 0.0101 \\
\hline High & 0.0219 & 0.0126 & 0.0036 & $0.0183^{* *}$ & More & 0.0214 & 0.0138 & 0.0067 & $0.0147^{* *}$ \\
\hline \multicolumn{5}{|c|}{ Turnover $\times$ Gubapost portfolio } & \multicolumn{5}{|c|}{ Dollar trading volume $\times$ Gubapost portfolio } \\
\hline Low & 0.0204 & 0.0157 & 0.0099 & 0.0105 & Low & 0.0268 & 0.0238 & 0.0196 & $0.0071^{* *}$ \\
\hline Medium & 0.0244 & 0.0165 & 0.0085 & $0.0159^{*}$ & Medium & 0.0179 & 0.0170 & 0.0092 & $0.0087^{* * *}$ \\
\hline High & 0.0247 & 0.0114 & 0.0014 & $0.0233^{* * *}$ & High & 0.0160 & 0.0102 & 0.0040 & $0.0120^{* *}$ \\
\hline \multicolumn{5}{|c|}{$R_{\max } \times$ Gubapost portfolio } & \multicolumn{5}{|c|}{$R_{t-1} \times$ Gubapost portfolio } \\
\hline Low & 0.0236 & 0.0165 & 0.0085 & $0.0151^{* *}$ & Low & 0.0249 & 0.0236 & 0.0100 & $0.0148^{* *}$ \\
\hline Medium & 0.0244 & 0.0148 & 0.0099 & $0.0144^{*}$ & Medium & 0.0246 & 0.0146 & 0.0082 & $0.0165^{* *}$ \\
\hline High & 0.0193 & 0.0132 & 0.0072 & 0.0122 & High & 0.0166 & 0.0114 & 0.0041 & 0.0125 \\
\hline \multicolumn{5}{|c|}{ Gross profitability $\times$ Gubapost portfolio } & \multicolumn{5}{|c|}{ Analyst coverage $\times$ Gubapost portfolio } \\
\hline Low & 0.0212 & 0.0121 & 0.0072 & $0.0139^{* *}$ & Low & 0.0265 & 0.0162 & 0.0063 & $0.0202^{* * *}$ \\
\hline Medium & 0.0221 & 0.0127 & 0.0085 & $0.0136^{*}$ & Medium & 0.0221 & 0.0146 & 0.0073 & $0.0148^{* *}$ \\
\hline High & 0.0225 & 0.0157 & 0.0058 & $0.0167^{* *}$ & High & 0.0197 & 0.0146 & 0.0075 & 0.0122 \\
\hline
\end{tabular}


This table shows the summary statistics and correlation matrix for the average monthly returns of the risk factors used in this study. The construction of the factors $M k t, S M B, H M L, U M D, R M W$, CMA, LIQ is consistent with the studies of Fama and French (1993), Carhart (1997), Fama and French (2015), and Pastor and Stambaugh (2003). SMF is the social media factor and is constructed using the difference between the VW returns of the lowest and highest $1 / 3$ of the portfolios, sorted by the last month Gubapost. MMF is the mass media factor and is constructed using the difference between the VW returns of the portfolios of stocks with no media coverage and the portfolios of stocks whose media coverage exceeds the median level.

\begin{tabular}{|c|c|c|c|c|c|c|c|c|c|}
\hline \multicolumn{10}{|c|}{ Panel A: Summary statistics } \\
\hline & SMF & MMF & Mkt & SMB & HML & UMD & RMW & CMA & LIQ \\
\hline Mean & 0.0154 & 0.0136 & 0.0077 & 0.0145 & 0.0021 & 0.0016 & -0.0058 & 0.0045 & 0.0060 \\
\hline Std dev. & 0.0636 & 0.0579 & 0.0738 & 0.0544 & 0.0454 & 0.0505 & 0.0312 & 0.0195 & 0.0258 \\
\hline Median & 0.0135 & 0.0132 & 0.0097 & 0.0138 & 0.0025 & 0.0081 & -0.0073 & 0.0036 & 0.0026 \\
\hline Min & -0.3039 & -0.2513 & -0.2511 & -0.1999 & -0.1648 & -0.1974 & -0.0868 & -0.0378 & -0.0393 \\
\hline $\operatorname{Max}$ & 0.2905 & 0.2274 & 0.1670 & 0.2015 & 0.1915 & 0.1463 & 0.0914 & 0.0636 & 0.0880 \\
\hline Skewness & -0.6760 & -0.7222 & -0.4337 & -0.2451 & 0.3486 & -0.5066 & 0.2782 & 0.5100 & 1.1003 \\
\hline Kurtosis & 15.9914 & 10.4936 & 4.7582 & 6.9479 & 8.7261 & 6.0287 & 4.1680 & 3.9467 & 4.9241 \\
\hline \multicolumn{10}{|c|}{ Panel B: Correlation matrix } \\
\hline & SMF & MMF & Mkt & SMB & HML & UMD & RMW & CMA & LIQ \\
\hline SMF & 1.0000 & & & & & & & & \\
\hline MMF & 0.8759 & 1.0000 & & & & & & & \\
\hline Mkt & 0.1403 & 0.1627 & 1.0000 & & & & & & \\
\hline SMB & 0.8652 & 0.8924 & 0.3113 & 1.0000 & & & & & \\
\hline HML & -0.8925 & -0.7842 & -0.1851 & -0.8144 & 1.0000 & & & & \\
\hline UMD & 0.3665 & 0.1717 & -0.0373 & 0.3209 & -0.3120 & 1.0000 & & & \\
\hline RMW & -0.6657 & -0.7686 & -0.4047 & -0.8659 & 0.5886 & -0.3214 & 1.0000 & & \\
\hline CMA & -0.0562 & 0.1768 & 0.1721 & 0.1991 & 0.2180 & 0.0693 & -0.4606 & 1.0000 & \\
\hline LIQ & -0.3946 & -0.2223 & 0.1570 & -0.1423 & 0.3470 & -0.2721 & -0.0233 & 0.3077 & 1.0000 \\
\hline
\end{tabular}


Table 4: Factor redundancy test for SMF

This table shows the results of regressing the returns of the long-short portfolio of Gubapost on commonly used risk factors. A significant intercept of a regression indicates that the corresponding risk factors cannot fully explain the excess return of the portfolio. $S M F$ is the dependent variable, and columns (2) and (3) add $L I Q$ and $M M F$ to control the liquidity risk and mass media effect, respectively. $t$-values are in parentheses. ${ }^{*},{ }^{* *}$, and ${ }^{* * *}$ indicate statistical significance at the $10 \%, 5 \%$, and $1 \%$ levels, respectively.

\begin{tabular}{|c|c|c|c|c|c|c|c|c|c|}
\hline & \multicolumn{3}{|c|}{ (1) } & \multicolumn{3}{|c|}{$(2)$} & \multicolumn{3}{|c|}{ (3) } \\
\hline Mkt & $-0.088^{* *}$ & $-0.081^{*}$ & $-0.085^{*}$ & -0.064 & -0.061 & -0.064 & -0.035 & $\begin{array}{l}-0.020 \\
\end{array}$ & -0.031 \\
\hline & $(-2.032)$ & $(-1.860)$ & $(-1.861)$ & $(-1.564)$ & $(-1.492)$ & $(-1.501)$ & $(-0.907)$ & $(-0.521)$ & $(-0.758)$ \\
\hline SMB & $\begin{array}{c}0.537^{* * *} \\
(5.395)\end{array}$ & $\begin{array}{c}0.520^{* * *} \\
(5.167)\end{array}$ & $\begin{array}{c}0.588^{* * *} \\
(3.407)\end{array}$ & $\begin{array}{c}0.600^{* * *} \\
(6.330)\end{array}$ & $\begin{array}{c}0.590^{* * *} \\
(6.067)\end{array}$ & $\begin{array}{c}0.599^{* * *} \\
(3.712)\end{array}$ & $\begin{array}{l}0.305^{* *} \\
(2.363)\end{array}$ & $\begin{array}{c}0.197 \\
(1.427)\end{array}$ & $\begin{array}{l}0.360^{* *} \\
(2.158)\end{array}$ \\
\hline HML & $\begin{array}{c}-0.753^{* * *} \\
(-6.521)\end{array}$ & $\begin{array}{c}-0.744^{* * *} \\
(-6.430)\end{array}$ & $\begin{array}{c}-0.715^{* * *} \\
(-4.559)\end{array}$ & $\begin{array}{c}-0.608^{* * *} \\
(-5.208)\end{array}$ & $\begin{array}{r}-0.608^{* * *} \\
(-5.181)\end{array}$ & $\begin{array}{c}-0.600^{* * *} \\
(-3.998)\end{array}$ & $\begin{array}{c}-0.558^{* * *} \\
(-5.072)\end{array}$ & $\begin{array}{c}-0.548^{* * *} \\
(-5.088)\end{array}$ & $\begin{array}{c}-0.482^{\text {*** }} \\
(-3.348)\end{array}$ \\
\hline UMD & & $\begin{array}{c}0.069 \\
(1.077)\end{array}$ & & & $\begin{array}{c}0.031 \\
(0.507)\end{array}$ & & & $\begin{array}{l}0.115^{*} \\
(1.915)\end{array}$ & \\
\hline RMW & & & $\begin{array}{c}0.045 \\
(0.179)\end{array}$ & & & $\begin{array}{c}-0.016 \\
(-0.056)\end{array}$ & & & $\begin{array}{c}0.032 \\
(0.156)\end{array}$ \\
\hline CMA & & & $\begin{array}{c}-0.059 \\
(-0.243)\end{array}$ & & & $\begin{array}{c}-0.023 \\
(-0.079)\end{array}$ & & & $\begin{array}{c}-0.145 \\
(-0.654)\end{array}$ \\
\hline LIQ & & & & $\begin{array}{c}-0.392^{* * *} \\
(-3.220)\end{array}$ & $\begin{array}{c}-0.379^{* * *} \\
(-3.029)\end{array}$ & $\begin{array}{c}-0.392^{* * *} \\
(-3.136)\end{array}$ & $\begin{array}{c}-0.356^{* * *} \\
(-3.119)\end{array}$ & $\begin{array}{c}-0.299^{* *} \\
(-2.593)\end{array}$ & $\begin{array}{c}-0.342^{* * *} \\
(-2.925)\end{array}$ \\
\hline MMF & & & & & & & $\begin{array}{c}0.336^{* * *} \\
(3.151)\end{array}$ & $\begin{array}{c}0.418^{* * *} \\
(3.706)\end{array}$ & $\begin{array}{c}0.359^{* * *} \\
(3.221)\end{array}$ \\
\hline Intercept & $\begin{array}{c}0.010^{* * *} \\
(2.919)\end{array}$ & $\begin{array}{r}0.010^{* * *} \\
(2.943)\end{array}$ & $\begin{array}{c}0.010^{* * *} \\
(2.689)\end{array}$ & $\begin{array}{c}0.011^{* * *} \\
(3.415)\end{array}$ & $\begin{array}{r}0.011^{* * *} \\
(3.394)\end{array}$ & $\begin{array}{c}0.011^{* * *} \\
(3.240)\end{array}$ & $\begin{array}{c}0.010^{* * *} \\
(3.370)\end{array}$ & $\begin{array}{c}0.010^{* * *} \\
(3.375)\end{array}$ & $\begin{array}{c}0.009^{* * *} \\
(3.019)\end{array}$ \\
\hline$\overline{R^{2}}$ & 0.863 & 0.865 & 0.863 & 0.883 & 0.883 & 0.883 & 0.900 & 0.906 & 0.901 \\
\hline
\end{tabular}




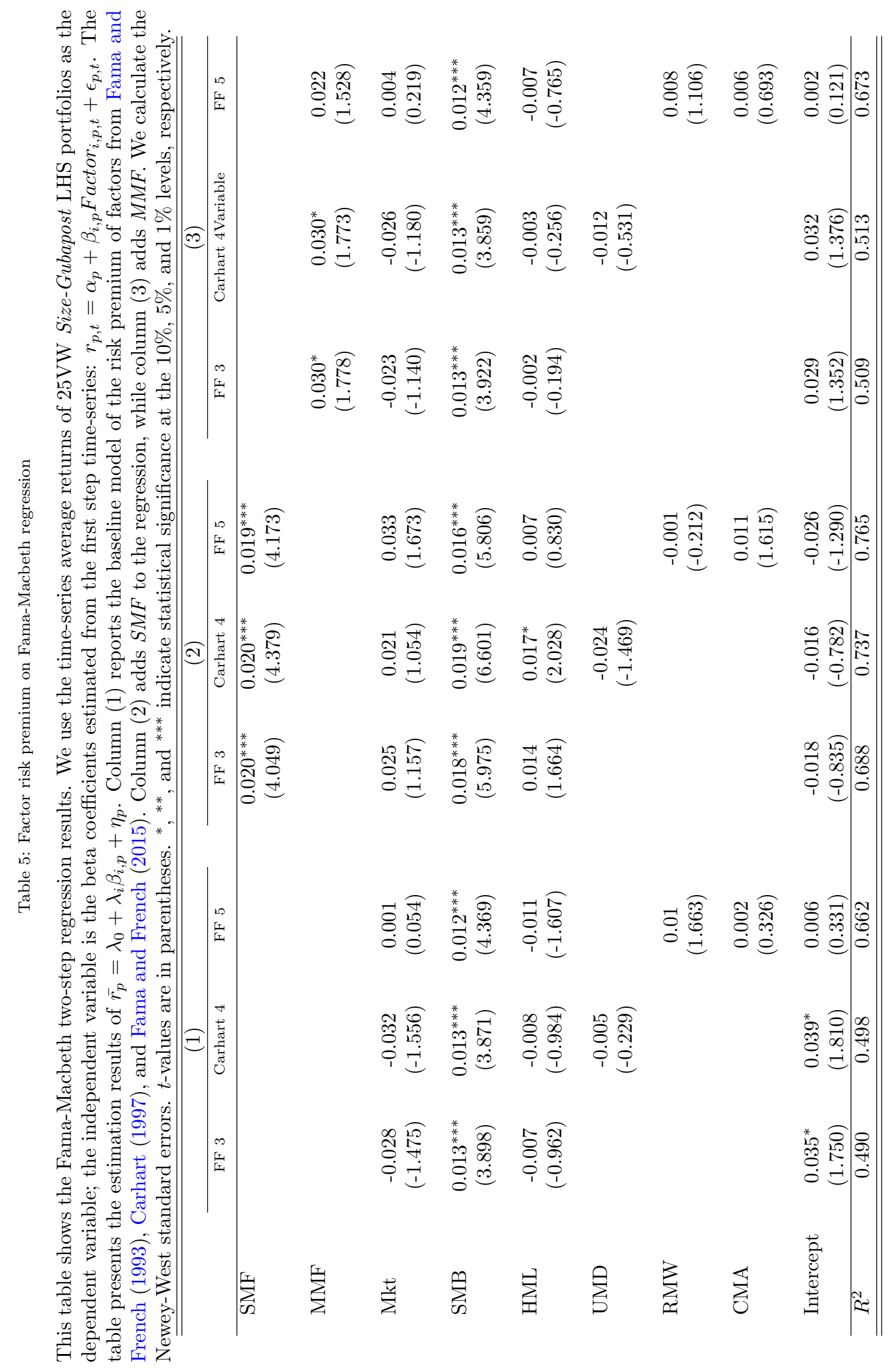


Table 6: The GRS test of the factor models

This table reports the test results of model performance of asset pricing models for the $25(5 \times 5)$ and $32(2 \times 4 \times 4)$ VW portfolios. The models are the Fama and French (1993) three-factor model with $M k t, S M B$ and $H M L$, Carhart (1997) four-factor model with $M k t, S M B, H M L$ and $U M D$, and Fama and French (2015) five-factor model with $M k t, S M B, H M L, R M W$ and $C M A$. The test statistics for models with and without $S M F$ are reported in columns (1) and (2), respectively. $p(G R S)$ is the p-value of the GRS statistic, which tests whether the expected values of all intercepts are zero. $A\left|\alpha_{i}\right|$ is the average absolute value of intercepts. totalMAPE is the total mean absolute pricing error measured by $|\alpha|+\frac{1}{N}|\epsilon| . a d j . R^{2}$ is average adjusted R-square of the time-series regression.

\begin{tabular}{|c|c|c|c|c|c|c|c|c|}
\hline & \multicolumn{4}{|c|}{ (1) } & \multicolumn{4}{|c|}{ (2) } \\
\hline & $p(G R S)$ & $A\left|\alpha_{i}\right|$ & $M A P E$ & $\operatorname{adj} . R^{2}$ & $p(G R S)$ & $A\left|\alpha_{i}\right|$ & $M A P E$ & $\operatorname{adj} . R^{2}$ \\
\hline \multicolumn{9}{|c|}{25 Size-B/M portfolios } \\
\hline FF 3 & 0.0127 & 0.0027 & 0.0173 & 0.9597 & 0.0351 & 0.0029 & 0.0171 & 0.9610 \\
\hline Carhart 4 & 0.0099 & 0.0027 & 0.0169 & 0.9614 & 0.0293 & 0.0029 & 0.0168 & 0.9628 \\
\hline FF 5 & 0.0125 & 0.0028 & 0.0172 & 0.9598 & 0.0353 & 0.0027 & 0.0168 & 0.9612 \\
\hline \multicolumn{9}{|c|}{25 Size-Gubapost portfolios } \\
\hline FF 3 & 0.0060 & 0.0061 & 0.0222 & 0.9427 & 0.0272 & 0.0043 & 0.0191 & 0.9525 \\
\hline Carhart 4 & 0.0032 & 0.0061 & 0.0221 & 0.9436 & 0.0180 & 0.0042 & 0.0189 & 0.9537 \\
\hline FF 5 & 0.0150 & 0.0057 & 0.0217 & 0.9431 & 0.0485 & 0.0040 & 0.0186 & 0.9532 \\
\hline \multicolumn{9}{|c|}{ 32 Size-B/M-Gubapost portfolios } \\
\hline FF 3 & 0.0714 & 0.0058 & 0.0237 & 0.9649 & 0.2069 & 0.0045 & 0.0213 & 0.9684 \\
\hline Carhart 4 & 0.0818 & 0.0058 & 0.0233 & 0.9651 & 0.2234 & 0.0046 & 0.0208 & 0.9682 \\
\hline FF 5 & 0.1429 & 0.0056 & 0.0233 & 0.9641 & 0.3227 & 0.0044 & 0.0209 & 0.9678 \\
\hline
\end{tabular}


Table 7: Investor recognition and Gubapost

This table shows Fama-Macbeth regressions of investor recognition proxies on Gubapost and mass media coverage. The dependent variables are logarithm of shareholder bases, the change of shareholder bases, mass media coverage and advertisement. Gubapost and Mass media are the respective amounts of social media posts and mass media coverage. Size is the market cap at the beginning of the month. Age is the number of days from the company's founding. 1/(share price) is the inverse of the median price in a given month. Return and Volatility are respectively the average and standard deviation of stock returns over the past three months. The regressions are estimated quarterly. We use the Newey-West method to adjust standard errors. $t$-values are in parentheses. ${ }^{*},{ }^{* *}$, and ${ }^{* * *}$ indicate statistical significance at the $10 \%, 5 \%$, and $1 \%$ levels, respectively.

\begin{tabular}{lcccc}
\hline \hline & $(1)$ & $(2)$ & $(3)$ & $(4)$ \\
& $\ln ($ Shareholder $)$ & $\Delta$ Shareholder & $\ln ($ Mass media) & $\ln ($ Advertisement) \\
\hline $\ln$ (Gubapost) & $0.454^{* * *}$ & $0.031^{* * *}$ & $0.212^{* * *}$ & $0.079^{* *}$ \\
& $(25.018)$ & $(5.604)$ & $(23.111)$ & $(2.781)$ \\
$\ln$ (Mass media) & $-0.022^{* *}$ & $0.013^{* * *}$ & & $0.149^{* * *}$ \\
& $(-2.120)$ & $(5.075)$ & - & $(3.494)$ \\
$\ln$ (Size) & $0.397^{* * *}$ & 0.003 & $0.521^{* * *}$ & $-0.096^{* * *}$ \\
& $(28.015)$ & $(0.637)$ & $(29.646)$ & $(-3.064)$ \\
$\ln$ (Age) & $0.230^{* * *}$ & $-0.019^{* * *}$ & $-0.124^{* * *}$ & $0.170^{* * *}$ \\
& $(13.985)$ & $(-3.791)$ & $(-6.148)$ & $(3.603)$ \\
$1 /$ (share price) & $5.699^{* * *}$ & -0.072 & $-1.554^{* * *}$ & $-4.827^{* * *}$ \\
& $(22.331)$ & $(-0.790)$ & $(-5.392)$ & $(-3.568)$ \\
Return & $-0.367^{* * *}$ & $-0.194^{* * *}$ & $0.198^{* *}$ & 0.210 \\
& $(-8.756)$ & $(-8.454)$ & $(2.568)$ & $(0.938)$ \\
Volatility & $-10.978^{* * *}$ & $7.769^{* * *}$ & $32.054^{* * *}$ & $-27.309^{* * *}$ \\
& $(-6.813)$ & $(10.063)$ & $(12.759)$ & $(-3.286)$ \\
Intercept & $-3.876^{* * *}$ & $-0.387^{* * *}$ & $-10.522^{* * *}$ & $2.907^{* * *}$ \\
& $(-14.301)$ & $(-3.926)$ & $(-20.903)$ & $(3.336)$ \\
\hline$R^{2}$ & 0.816 & 0.155 & 0.485 & 0.045 \\
\hline \hline
\end{tabular}


Table 8: Shareholder base regressions grouped by shareholder base and Gubapost

We double-sort stocks into four groups according to the shareholder base and Gubapost. This table shows Fama-Macbeth shareholder base regression results for each group. The variables are the same as in Table 7 . The regressions are estimated quarterly: $\ln$ (numbers of shareholders) $=$ $\alpha+\beta \ln ($ Gubapost $)+\gamma_{i}$ control $_{i}+\epsilon$. We calculate the Newey-West standard errors. $t$-values are in parentheses. ${ }^{*},{ }^{* *}$, and ${ }^{* * *}$ indicate statistical significance at the $10 \%, 5 \%$, and $1 \%$ levels, respectively.

\begin{tabular}{|c|c|c|c|c|}
\hline & $\begin{array}{c}\text { (1) } \\
\text { Low Gubapost } \\
\text { Low Shareholders }\end{array}$ & $\begin{array}{c}\text { (2) } \\
\text { Low Gubapost } \\
\text { High Shareholders }\end{array}$ & $\begin{array}{c}(3) \\
\text { High Gubapost } \\
\text { Low Shareholders }\end{array}$ & $\begin{array}{c}\text { (4) } \\
\text { High Gubapost } \\
\text { High Shareholders }\end{array}$ \\
\hline $\ln$ (Gubapost) & $\begin{array}{l}0.408^{* * *} \\
(25.749)\end{array}$ & $\begin{array}{l}0.161^{* * *} \\
(10.599)\end{array}$ & $\begin{array}{l}0.189^{* * *} \\
(13.654)\end{array}$ & $\begin{array}{l}0.320^{* * *} \\
(11.610)\end{array}$ \\
\hline $\ln$ (Mass media) & $\begin{array}{c}-0.021^{* *} \\
(-2.259)\end{array}$ & $\begin{array}{c}-0.021^{* * *} \\
(-3.958)\end{array}$ & $\begin{array}{c}-0.009 \\
(-1.251)\end{array}$ & $\begin{array}{c}-0.007 \\
(-0.856)\end{array}$ \\
\hline $\ln ($ Size $)$ & $\begin{array}{l}0.239^{* * *} \\
(24.342)\end{array}$ & $\begin{array}{l}0.295^{* * *} \\
(19.638)\end{array}$ & $\begin{array}{l}0.182^{* * *} \\
(13.647)\end{array}$ & $\begin{array}{l}0.373^{* * *} \\
(30.586)\end{array}$ \\
\hline $\ln ($ Age $)$ & $\begin{array}{l}0.174^{* * *} \\
(11.655)\end{array}$ & $\begin{array}{c}0.100^{* * *} \\
(9.112)\end{array}$ & $\begin{array}{c}0.122^{* * *} \\
(7.736)\end{array}$ & $\begin{array}{c}0.141^{* * *} \\
(9.751)\end{array}$ \\
\hline 1/(share price) & $\begin{array}{l}6.040^{* * *} \\
(16.203)\end{array}$ & $\begin{array}{l}3.287^{* * *} \\
(22.915)\end{array}$ & $\begin{array}{l}4.279^{* * *} \\
(17.603)\end{array}$ & $\begin{array}{l}3.863^{\text {*** }} \\
(17.401)\end{array}$ \\
\hline Return & $\begin{array}{c}-0.387^{* * *} \\
(-9.981)\end{array}$ & $\begin{array}{c}-0.334^{* * *} \\
(-3.941)\end{array}$ & $\begin{array}{c}-0.221^{* * *} \\
(-6.563)\end{array}$ & $\begin{array}{c}-0.154^{* * *} \\
(-4.530)\end{array}$ \\
\hline Volatility & $\begin{array}{c}-9.155^{* * *} \\
(-6.356)\end{array}$ & $\begin{array}{c}-4.209^{* *} \\
(-2.671)\end{array}$ & $\begin{array}{c}-1.067 \\
(-1.043)\end{array}$ & $\begin{array}{c}-9.581^{* * *} \\
(-6.469)\end{array}$ \\
\hline Intercept & $\begin{array}{c}0.174 \\
(0.633) \\
\end{array}$ & $\begin{array}{c}2.065^{* * *} \\
(5.527)\end{array}$ & $\begin{array}{c}3.303^{* * *} \\
(7.217)\end{array}$ & $\begin{array}{c}-1.242^{* * *} \\
(-6.460)\end{array}$ \\
\hline$R^{2}$ & 0.650 & 0.484 & 0.418 & 0.723 \\
\hline
\end{tabular}


Table 9: Monthly excess returns of $25 \mathrm{VW}$ portfolios in different sentiment groups

This table reports average monthly excess returns for $25(5 \times 5)$ VW portfolios formed on Size and Gubapost over 65 months. At the beginning of each month, stocks are allocated to five Size groups (Small to Big) by market cap, and allocated equally to five Gubapost groups (Low to High) by the average number of Guba posts in the last month. The intersections of these two sorts produce three 25 value-weight Size-Gubapost portfolios. Columns L-H show the difference between the returns of the low and high quintile of Gubapost portfolios. Correspondingly, rows S-B show the average returns of Small size portfolios minus those of Big size portfolios. Panels A-C separately report the results of different sentiment groups (negative, neutral, positive) $.{ }^{*},{ }^{* *}$, and ${ }^{* * *}$ indicate statistical significance at the $10 \%, 5 \%$, and $1 \%$ levels, respectively.

\begin{tabular}{|c|c|c|c|c|c|c|c|}
\hline \multicolumn{8}{|c|}{ Panel A Size $\times$ Negative Gubapost portfolio } \\
\hline & & \multicolumn{6}{|c|}{ Gubapost } \\
\hline & & low & 2 & 3 & 4 & High & L-H \\
\hline \multirow{6}{*}{ Size } & small & 0.037 & 0.034 & 0.028 & 0.021 & 0.010 & $0.027^{* * *}$ \\
\hline & 2 & 0.032 & 0.026 & 0.021 & 0.016 & 0.002 & $0.030^{* * *}$ \\
\hline & 3 & 0.027 & 0.022 & 0.017 & 0.011 & 0.007 & $0.020^{* * *}$ \\
\hline & 4 & 0.021 & 0.017 & 0.013 & 0.014 & 0.007 & $0.013^{* * *}$ \\
\hline & big & 0.017 & 0.015 & 0.016 & 0.013 & 0.004 & $0.013^{* *}$ \\
\hline & S-B & $0.020^{* *}$ & $0.019^{* *}$ & 0.012 & 0.008 & 0.006 & \\
\hline
\end{tabular}

\begin{tabular}{cccccccc}
\hline \multicolumn{2}{c}{ Panel B Size $\times$ Neutral Gubapost portfolio } \\
\hline & low & 2 & Gubapost & High & L-H \\
\hline \multirow{4}{*}{ Size } & small & 0.039 & 0.033 & 0.026 & 0.021 & 0.014 & $0.025^{* * *}$ \\
& 2 & 0.034 & 0.024 & 0.023 & 0.016 & 0.000 & $0.034^{* * *}$ \\
& 3 & 0.027 & 0.021 & 0.017 & 0.013 & 0.006 & $0.021^{* * *}$ \\
& 4 & 0.021 & 0.016 & 0.015 & 0.011 & 0.009 & $0.012^{* *}$ \\
& big & 0.013 & 0.014 & 0.014 & 0.015 & 0.006 & 0.008 \\
& S-B & $0.026^{* * *}$ & $0.019^{* *}$ & $0.012^{*}$ & 0.006 & 0.008 & \\
\hline
\end{tabular}

\begin{tabular}{|c|c|c|c|c|c|c|c|}
\hline \multicolumn{8}{|c|}{ Panel C Size $\times$ Positive Gubapost portfolio } \\
\hline & & low & 2 & 3 & 4 & High & L-H \\
\hline \multirow{6}{*}{ Size } & small & 0.038 & 0.035 & 0.026 & 0.020 & 0.017 & $0.021^{* * *}$ \\
\hline & 2 & 0.033 & 0.027 & 0.021 & 0.016 & 0.000 & $0.034^{* * *}$ \\
\hline & 3 & 0.025 & 0.026 & 0.016 & 0.010 & 0.008 & $0.017^{* * *}$ \\
\hline & 4 & 0.021 & 0.015 & 0.016 & 0.012 & 0.008 & $0.014^{* * *}$ \\
\hline & big & 0.013 & 0.014 & 0.013 & 0.013 & 0.006 & 0.006 \\
\hline & S-B & $0.025^{* * *}$ & $0.021^{* * *}$ & $0.013^{*}$ & 0.007 & 0.010 & \\
\hline
\end{tabular}


Table 10: Factor redundancy test for SMF on sentiment factors.

This table shows the results of regressing the returns of the long-short portfolio of Gubapost on sentiment factors: $S M F_{t}=\alpha+\beta$ Sentiment Factor $s_{t}+\lambda$ Control Factors $+\epsilon_{t}$. A significant intercept in the regression indicates that the sentiment factors cannot fully explain the excess return of the portfolio. SMF is the dependent variable and TurnoverF, VolumeF, and MAXF are the independent variables. We also control for commonly used factors, the mass media factor, and the liquidity factor. $t$-values are in parentheses. ${ }^{*},{ }^{* *}$, and ${ }^{* * *}$ indicate statistical significance at the $10 \%, 5 \%$, and $1 \%$ levels, respectively.

\begin{tabular}{|c|c|c|c|}
\hline TurnoverF & $\begin{array}{c}(1) \\
0.201 \\
(1.558)\end{array}$ & $\begin{array}{c}(2) \\
0.210^{*} \\
(1.784)\end{array}$ & $\begin{array}{c}(3) \\
0.228^{*} \\
(1.765)\end{array}$ \\
\hline VolumeF & $\begin{array}{c}0.436^{* * *} \\
(3.135)\end{array}$ & $\begin{array}{c}0.451^{* * *} \\
(3.270)\end{array}$ & $\begin{array}{c}0.417^{* * *} \\
(3.032)\end{array}$ \\
\hline MAXF & $\begin{array}{c}-0.010 \\
(-0.084)\end{array}$ & $\begin{array}{c}-0.027 \\
(-0.261)\end{array}$ & $\begin{array}{c}-0.031 \\
(-0.271)\end{array}$ \\
\hline Mkt & $\begin{array}{c}0.024 \\
(0.400)\end{array}$ & $\begin{array}{c}0.035 \\
(0.640)\end{array}$ & $\begin{array}{c}0.023 \\
(0.393)\end{array}$ \\
\hline SMB & $\begin{array}{c}0.215 \\
(1.278)\end{array}$ & $\begin{array}{c}0.098 \\
(0.580)\end{array}$ & $\begin{array}{c}0.245 \\
(1.277)\end{array}$ \\
\hline HML & $\begin{array}{c}-0.535^{* * *} \\
(-3.574)\end{array}$ & $\begin{array}{c}-0.523^{* * *} \\
(-3.524)\end{array}$ & $\begin{array}{c}-0.494^{* * *} \\
(-2.868)\end{array}$ \\
\hline UMD & & $\begin{array}{c}0.117^{* * *} \\
(2.808)\end{array}$ & \\
\hline RMW & & & $\begin{array}{c}-0.055 \\
(-0.303)\end{array}$ \\
\hline CMA & & & $\begin{array}{c}-0.149 \\
(-0.689)\end{array}$ \\
\hline MMF & $\begin{array}{c}0.103 \\
(0.956)\end{array}$ & $\begin{array}{l}0.183^{*} \\
(1.713)\end{array}$ & $\begin{array}{c}0.125 \\
(1.376)\end{array}$ \\
\hline LIQ & $\begin{array}{c}-0.354^{* * *} \\
(-4.720)\end{array}$ & $\begin{array}{c}-0.297^{* * *} \\
(-4.804)\end{array}$ & $\begin{array}{c}-0.347^{* * *} \\
(-4.546)\end{array}$ \\
\hline Intercept & $\begin{array}{l}0.006^{* *} \\
(2.451)\end{array}$ & $\begin{array}{l}0.006^{* *} \\
(2.344)\end{array}$ & $\begin{array}{l}0.006^{* *} \\
(2.267)\end{array}$ \\
\hline$R^{2}$ & 0.928 & 0.934 & 0.929 \\
\hline
\end{tabular}




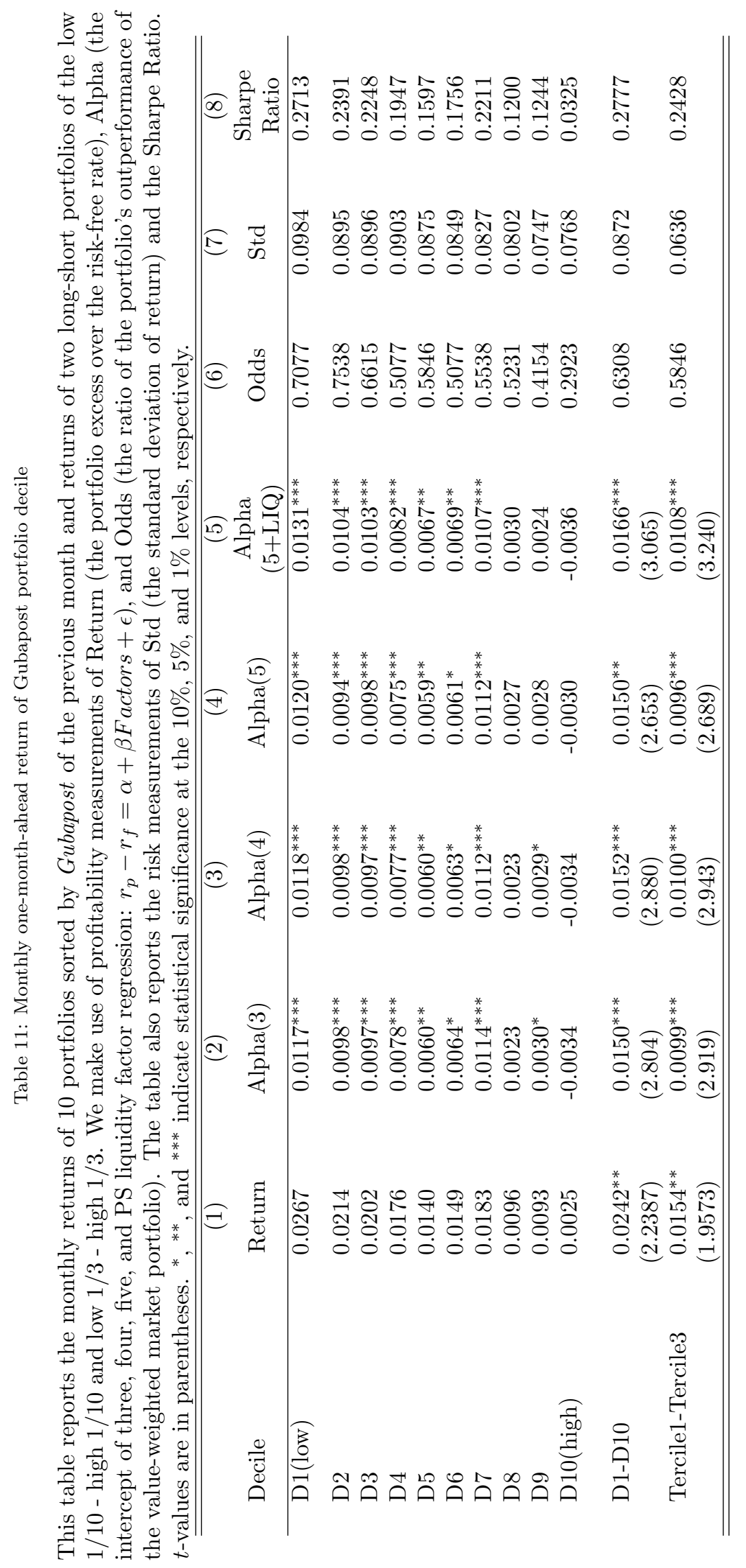


Table 12: Trading profits grouped by firm characteristics

This table examines the profitability of a social media effect trading strategy in sub-samples of stocks sorted by various firm characteristics. Each month, stocks are sorted into 10 Gubapost portfolios, and the portfolio goes the long position on the lowest $10 \%$ and a short position on the highest 10\% of Gubapost. The long and short legs of the portfolio invest an equal amount in each underlying stock, and portfolio weights are rebalanced monthly. We report alphas from regressing the resulting time series of long-short portfolio returns on the market factor, the Fama-French three-factor, Carhart four-factor, Fama-French five-factor, and Pastor-Stambaugh liquidity factor models. $t$-values are in parentheses. ${ }^{*}, * *$, and ${ }^{* * *}$ indicate statistical significance at the $10 \%, 5 \%$, and $1 \%$ levels, respectively.

\begin{tabular}{|c|c|c|c|c|}
\hline FF 3 & Carhart 4 & & FF 5 & LIQ \\
\hline \multicolumn{5}{|c|}{ Panel A: By Firm Size } \\
\hline & & \multirow[t]{2}{*}{ Small } & & \\
\hline $\begin{array}{c}0.025^{* * *} \\
(4.265)\end{array}$ & $\begin{array}{c}0.025^{* * *} \\
(4.267)\end{array}$ & & $\begin{array}{c}0.022^{* * *} \\
(3.683)\end{array}$ & $\begin{array}{c}0.023^{* * *} \\
(3.828)\end{array}$ \\
\hline & & \multirow[t]{2}{*}{ Medium } & & \\
\hline $\begin{array}{c}0.023^{* * *} \\
(3.953)\end{array}$ & $\begin{array}{c}0.023^{* * *} \\
(3.948)\end{array}$ & & $\begin{array}{c}0.020^{* * *} \\
(3.428)\end{array}$ & $\begin{array}{c}0.021^{* * *} \\
(3.437)\end{array}$ \\
\hline $\begin{array}{c}0.012^{* * *} \\
(2.689) \\
\end{array}$ & $\begin{array}{c}0.012^{* * *} \\
(2.672) \\
\end{array}$ & Big & $\begin{array}{c}0.011^{* *} \\
(2.463) \\
\end{array}$ & $\begin{array}{r}0.012^{* * *} \\
(2.770) \\
\end{array}$ \\
\hline \multicolumn{5}{|c|}{ Panel B: By Book-to-Market } \\
\hline & & \multirow[t]{2}{*}{ Low } & & \\
\hline $\begin{array}{c}0.019^{* * *} \\
(3.486)\end{array}$ & $\begin{array}{c}0.019^{* * *} \\
(3.499)\end{array}$ & & $\begin{array}{c}0.018^{* * *} \\
(3.151)\end{array}$ & $\begin{array}{c}0.019^{* * *} \\
(3.540)\end{array}$ \\
\hline $\begin{array}{c}0.017^{* * *} \\
(2.965)\end{array}$ & $\begin{array}{c}0.017^{* * *} \\
(3.009)\end{array}$ & Medium & $\begin{array}{c}0.014^{* *} \\
(2.485)\end{array}$ & $\begin{array}{c}0.016^{* * *} \\
(2.855)\end{array}$ \\
\hline $\begin{array}{c}0.010^{*} \\
(1.933)\end{array}$ & $\begin{array}{l}0.010^{*} \\
(1.934)\end{array}$ & High & $\begin{array}{l}0.009^{*} \\
(1.755)\end{array}$ & $\begin{array}{l}0.010^{*} \\
(1.851)\end{array}$ \\
\hline \multicolumn{5}{|c|}{ Panel C: By Past 12-Month Momentum } \\
\hline & & \multirow[t]{2}{*}{ Low } & & \\
\hline $\begin{array}{c}0.011^{* *} \\
(2.304)\end{array}$ & $\begin{array}{l}0.011^{* *} \\
(2.310)\end{array}$ & & $\begin{array}{c}0.011^{* *} \\
(2.111)\end{array}$ & $\begin{array}{l}0.011^{* *} \\
(2.205)\end{array}$ \\
\hline $\begin{array}{l}0.012^{*} \\
(1.952)\end{array}$ & $\begin{array}{l}0.012^{*} \\
(1.938)\end{array}$ & Medium & $\begin{array}{c}0.011^{*} \\
(1.784)\end{array}$ & $\begin{array}{l}0.012^{*} \\
(1.858)\end{array}$ \\
\hline $\begin{array}{c}0.021^{* * *} \\
(2.897)\end{array}$ & $\begin{array}{c}0.021^{* * *} \\
(2.869)\end{array}$ & High & $\begin{array}{c}0.020^{* *} \\
(2.653)\end{array}$ & $\begin{array}{r}0.022^{* * *} \\
(2.837)\end{array}$ \\
\hline
\end{tabular}


Table 13: Trading profits grouped by liquidity and sentiment characteristics

This table examines the profitability of a social media effect trading strategy in sub-samples of firms sorted by various liquidity and sentiment proxies. Each month, stocks are sorted into 10 Gubapost portfolios, and the portfolio goes long on the lowest $10 \%$ and short on the highest $10 \%$ of Gubapost. The long and short legs of the portfolio invest an equal amount in each underlying stock, and portfolio weights are rebalanced monthly. The reported numbers are alphas obtained by regressing the resulting time series of zero-investment portfolio returns on the market factor, Fama-French three-factor, Carhart four-factor, Fama-French five-factor, and Pastor-Stambaugh liquidity factor models. Note that in Panel B, Dollar Trading Volume is a proxy of both liquidity and sentiment. $t$-values are in parentheses. *, ${ }^{* *}$, and ${ }^{* * *}$ indicate statistical significance at the $10 \%, 5 \%$, and $1 \%$ levels, respectively.

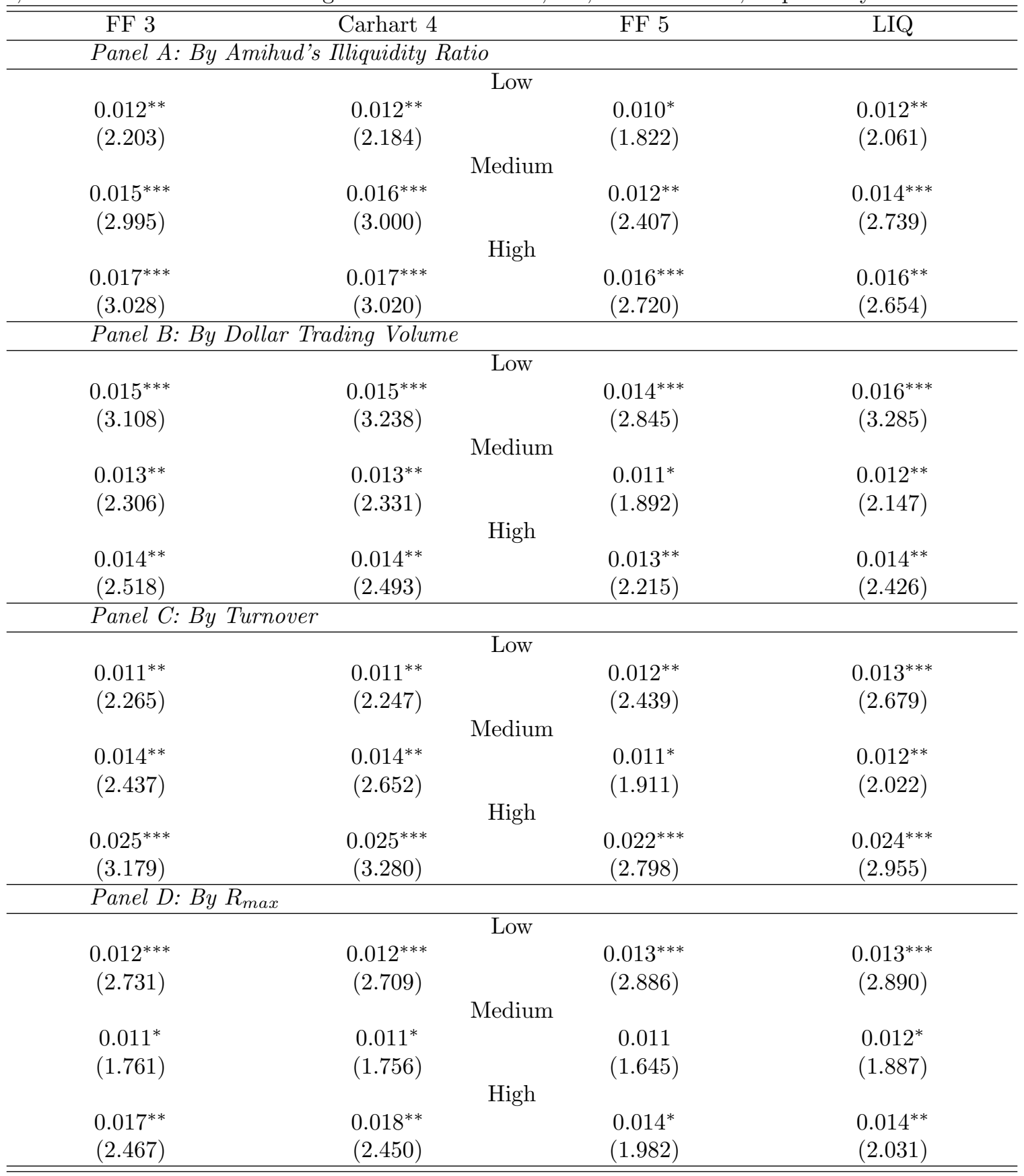


Table 14: Annual performance of social media effect strategy

This table reports the annual performance of the social media effect strategy. "Mean num of Stock" is the rounded average number of stock trades in the strategy. Five annualized returns in excess of the risk-free rate, VW market portfolio return, CSI 300, 500, 1000 (big, medium and small size) index returns are reported in the followed rows. "Odds" is the winning ratio by which the portfolio outperforms the VW market portfolio. "Sharpe Ratio" is the Sharpe ratio of the strategy. $t$-values are in parentheses. ${ }^{*},{ }^{* *}$, and ${ }^{* * *}$ indicate statistical significance at the $10 \%, 5 \%$, and $1 \%$ levels, respectively.

\begin{tabular}{lcc}
\hline \hline Mean num of & $\begin{array}{c}\text { buy-and-hold } \\
\text { portfolio }\end{array}$ & $\begin{array}{c}\text { long-short } \\
\text { portfolio }\end{array}$ \\
Stocks & 200 & $\begin{array}{c}200 \text { long \& } \\
200 \text { short }\end{array}$ \\
Annualizd & $0.3966^{* * *}$ & $0.3219^{* * *}$ \\
Return & $(6.8972)$ & $(8.5848)$ \\
Excess Return relevant & $0.2265^{* * *}$ & $0.1518^{* *}$ \\
to VW-Market Portfolio & $(9.0259)$ & $(2.0469)$ \\
Excess Return relevant & $0.2734^{* * *}$ & $0.1987^{* * *}$ \\
to CSI 300 Index Return & $(8.7269)$ & $(2.7099)$ \\
Excess Return relevant & $0.1950^{* * *}$ & $0.1203^{*}$ \\
to CSI 500 Index Return & $(7.0832)$ & $(1.7039)$ \\
Excess Return relevant & $0.1290^{* * *}$ & 0.0544 \\
to CSI 1000 Index Return & $(4.3559)$ & $(0.8066)$ \\
Odds & 0.9074 & 0.7593 \\
Sharpe Ratio & 0.9386 & 1.1682 \\
\hline \hline
\end{tabular}


Table 15: Factor redundant test for SMF on q-factors.

This table shows the results of regression on the time-series returns on the long-short portfolio of Gubapost and profitability and investment risk q-factors. The significant coefficient of the intercept indicates that the profitability and investment risk factors cannot explain the excess return of the portfolio. The regression uses $S M F$ as the dependent variable and q-factors as the independent variables, constructed from Hou et al. (2015). The regression is as follows: $S M F_{t}=\alpha+\beta$ Factor $s_{t}+\epsilon_{t}$. $t$-values are in parentheses. ${ }^{*},{ }^{* *}$, and ${ }^{* * *}$ indicate statistical significance at the $10 \%, 5 \%$, and $1 \%$ levels, respectively.

\begin{tabular}{cccc}
\hline \hline & $(1)$ & $(2)$ & $(3)$ \\
\hline Mkt & -0.040 & -0.036 & -0.008 \\
& $(-0.682)$ & $(-0.653)$ & $(-0.163)$ \\
q_size & $0.416^{* * *}$ & $0.429^{* * *}$ & 0.140 \\
& $(3.290)$ & $(3.592)$ & $(1.095)$ \\
q_inv & 0.074 & -0.003 & -0.118 \\
& $(0.434)$ & $(-0.021)$ & $(-0.803)$ \\
q-prof & -0.168 & -0.314 & -0.003 \\
& $(-0.875)$ & $(-1.665)$ & $(-0.014)$ \\
LIQ & & $-0.396^{* * *}$ & $-0.328^{* *}$ \\
& & $(-2.872)$ & $(-2.645)$ \\
MMF & & & $0.473^{* * *}$ \\
& & & $(4.043)$ \\
Intercept & & $0.014^{* * *}$ & $0.009^{* *}$ \\
& $(3.210)$ & $(3.780)$ & $(2.589)$ \\
\hline$R^{2}$ & 0.846 & 0.865 & 0.895 \\
\hline \hline
\end{tabular}


Table 16: Factor redundant test on STREV and parsimonious model test.

Column (1) of this table shows the results of regressing the returns of the long-short portfolio of Gubapost on sentiment factors: $S M F_{t}=\alpha+\beta S T R E V$ Factor $s_{t}+\lambda$ Control Factors $+\epsilon_{t}$. A significant intercept in the regression indicates that the short-term reversal effect cannot fully explain the excess return of the portfolio. $S M F$ is the dependent variable and STREV is the independent variables constructed by one-month stock returns . We also control for commonly used factors, the mass media factor, and the liquidity factor. Column (2) employ three kinds of parsimonious model combined significant factors as robustness check. $t$-values are in parentheses. ${ }^{*},{ }^{* *}$, and ${ }^{* * *}$ indicate statistical significance at the $10 \%, 5 \%$, and $1 \%$ levels, respectively.

\begin{tabular}{|c|c|c|c|c|c|c|}
\hline & & (1) & & & (2) & \\
\hline STERV & $\begin{array}{c}-0.030 \\
(-0.540)\end{array}$ & $\begin{array}{c}-0.038 \\
(-0.712)\end{array}$ & $\begin{array}{c}-0.029 \\
(-0.521)\end{array}$ & & $\begin{array}{c}0.011 \\
(0.188)\end{array}$ & $\begin{array}{c}-0.030 \\
(-0.545)\end{array}$ \\
\hline Mkt & $\begin{array}{c}-0.042 \\
(-1.020)\end{array}$ & $\begin{array}{c}-0.028 \\
(-0.693)\end{array}$ & $\begin{array}{c}-0.038 \\
(-0.868)\end{array}$ & $\begin{array}{c}-0.021 \\
(-0.521)\end{array}$ & $\begin{array}{l}-0.081^{*} \\
(-1.676)\end{array}$ & $\begin{array}{c}-0.037 \\
(-0.851)\end{array}$ \\
\hline SMB & $\begin{array}{c}0.281^{* *} \\
(2.055)\end{array}$ & $\begin{array}{c}0.163 \\
(1.116)\end{array}$ & $\begin{array}{l}0.338^{*} \\
(1.951)\end{array}$ & $\begin{array}{c}0.197 \\
(1.427)\end{array}$ & $\begin{array}{c}0.584^{* * *} \\
(3.408)\end{array}$ & $\begin{array}{c}0.333^{*} \\
(1.937)\end{array}$ \\
\hline HML & $\begin{array}{c}-0.575^{* * *} \\
(-5.001)\end{array}$ & $\begin{array}{c}-0.569^{* * *} \\
(-5.073)\end{array}$ & $\begin{array}{c}-0.501^{* * *} \\
(-3.359)\end{array}$ & $\begin{array}{c}-0.548^{* * *} \\
(-5.088)\end{array}$ & $\begin{array}{c}-0.730^{* * *} \\
(-5.544)\end{array}$ & $\begin{array}{c}-0.554^{* * *} \\
(-4.526)\end{array}$ \\
\hline UMD & & $\begin{array}{l}0.118^{*} \\
(1.959)\end{array}$ & & $\begin{array}{l}0.115^{*} \\
(1.915)\end{array}$ & & \\
\hline RMW & & & $\begin{array}{c}0.037 \\
(0.170)\end{array}$ & & $\begin{array}{c}0.077 \\
(0.346)\end{array}$ & $\begin{array}{c}0.100 \\
(0.509)\end{array}$ \\
\hline CMA & & & $\begin{array}{c}-0.137 \\
(-0.633)\end{array}$ & & & \\
\hline LIQ & $\begin{array}{c}-0.343^{* * *} \\
(-2.888)\end{array}$ & $\begin{array}{c}-0.280^{* *} \\
(-2.327)\end{array}$ & $\begin{array}{c}-0.329^{* * *} \\
(-2.707)\end{array}$ & $\begin{array}{c}-0.301^{* *} \\
(-2.593)\end{array}$ & & $\begin{array}{c}-0.335 * * * \\
(-2.772)\end{array}$ \\
\hline MMF & $\begin{array}{c}0.362^{* * *} \\
(3.075)\end{array}$ & $\begin{array}{c}0.454^{* * *} \\
(3.655)\end{array}$ & $\begin{array}{c}0.384^{* * *} \\
(3.141)\end{array}$ & $\begin{array}{c}0.418^{* * *} \\
(3.706)\end{array}$ & & $\begin{array}{c}0.372^{* * *} \\
(3.097)\end{array}$ \\
\hline Intercept & $\begin{array}{c}0.010^{* * *} \\
(3.390) \\
\end{array}$ & $\begin{array}{c}0.010^{* * *} \\
(3.422) \\
\end{array}$ & $\begin{array}{c}0.010^{* * *} \\
(3.039) \\
\end{array}$ & $\begin{array}{c}0.010^{* * *} \\
(3.375) \\
\end{array}$ & $\begin{array}{c}0.009^{* *} \\
(2.620) \\
\end{array}$ & $\begin{array}{c}0.010^{* * *} \\
(3.095)\end{array}$ \\
\hline$R^{2}$ & 0.900 & 0.907 & 0.901 & 0.906 & 0.863 & 0.901 \\
\hline
\end{tabular}


Table 17: Variable Definition

\begin{tabular}{ll}
\hline \hline \multicolumn{1}{c}{ Name } & \multicolumn{1}{c}{ Definition } \\
\hline Key Variables & The number of postings in each stock's sub-forum on \\
Gubapost & Guba.eastmoney.com, over the previous month. \\
& The social media factor: return of a portfolio of $1 / 3$ low Gubapost \\
SMF & stocks minus the return of a portfolio of $1 / 3$ high Gubapost stocks. \\
& \\
& The mass media factor: return of a portfolio of no-news-coverage \\
sMF & stocks minus the return of a portfolio of $1 / 2$ high-news-coverage \\
& stocks.
\end{tabular}

Control Variables

Size

Book-to-Market ratio (B/M)

Liquidity

Volatility

Price

Institutional holding

Momentum

Amihud's (2002) illiquidity ratio

Dollar trading volume

Turnover

$\mathrm{R}_{\max }$

$\mathrm{R}_{t-1}$

Gross profitability

Analyst coverage
Natural log of the average market capitalization of equity over the previous calendar year.

Natural log of the book value of equity divided by the market value of equity, as of the previous year end.

The inverse of Amihud's (2002) illiquidity ratio.

The standard deviation of returns over the past three months.

Average closing price during the previous month.

Percentage of the stock's outstanding shares owned by institutions.

Past 12-month return.

Stock's absolute return divided by its daily dollar trading volume.

Daily value of trades in a stock, averaged over all days in a month.

Daily turnover of a stock, measured by the ratio of trading volume on total liquidity capital and averaged over all days in a month.

Max daily return of a stock in the past month.

Monthly return of a stock in previous month.

Gross profits-to-assets ratio over the previous calendar year.

The number of analyst reports of a stock in the past month. 
Mkt

SMB

HML

UMD

RMW

CMA

LIQ

TurnoverF

VolumeF

MAXF

q_size

q_inv

q-prof

STREV
Value-weighted return of our sample minus return on $1 / 12$ annualized 3-month SHIBOR.

Return of a portfolio of $30 \%$ small stocks minus the return of a portfolio of $30 \%$ large stocks.

Return on a portfolio of stocks with $1 / 2$ high book-to-market ratio, minus return on a portfolio of stocks with $1 / 2$ low book-tomarket ratio.

Return on a portfolio of stocks with a high past 12-month return, minus the return on a portfolio of stocks with a low past 12-month return.

Profitability factor followed the construction of Fama and French (2015).

Investment factor followed the construction of Fama and French (2015).

Traded liquidity factor followed the construction of Pastor and Stambaugh (2003).

A sentiment factor: return of a portfolio of $1 / 3$ low turnover stocks minus the return of a portfolio of $1 / 3$ high turnover stocks.

A sentiment factor: return of a portfolio of $1 / 3$ low volume stocks minus the return of a portfolio of $1 / 3$ high volume stocks.

A sentiment factor: return of a portfolio of $1 / 3$ low $\mathrm{R}_{\max }$ stocks minus the return of a portfolio of $1 / 3$ high $\mathrm{R}_{\max }$ stocks.

Size factor of the q-factor model followed the construction of Hou et al. (2015).

Investment factor of the q-factor model followed the construction of Hou et al. (2015).

Profitability factor of the q-factor model followed the construction of Hou et al. (2015).

Short-term reversal factor constructed by one-month stock returns followed Han et al. (2019). 